\title{
التكلف اللغوي عند ابن جني 0392 في كتاب الخصائص- مظاهره وأسبابه
}

\author{
أماني عبد العزيز الداود \\ أستاذ مشارك في اللغة العربية- جامعة جدة- السعودية \\ aaal-dawood@uj.edu.sa
}


المجلة الدولية للدراسات اللغوية والأدبية العببية

International Journal for Arabic Linguistics and Literature Studies (JALLS)

التكلف اللغوي عند ابن جني 392هـ في كتاب الخصائص- مظاهره وأسبابه

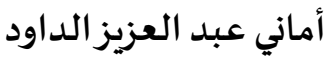

$$
\begin{aligned}
& \text { أستاذ مشارك في اللغة العربية- جامعة جدة- السعودية }
\end{aligned}
$$

aaal-dawood@uj.edu.sa

DOI: https://doi.org/10.31559/JALLS2021.3.3.4 2021/8/7 2021/7/7 مراجعة البحث: 2021/7/21 قبول البحث البحث: 201/2

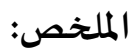

منزلة ابن جني العلمية وبراعته اللغوية نطقت بها شهادات المتقدمين والمتأخرين، وأشار إليها المحققون، فمكانته العلمية محل إجماع، لا نزاع حولها ولا خلاف، ومن هنا جاءت طبيعة هذه الدراسة مختلفة عن غيرها من الدراسات التي تناولت ابن جني في كونها تتوجه لإلقاء الضيوء على مأخذ من المآخذ التي أخذت عليه، وجانب من جوانب النقد اللغوي الذي وجها إليه، ذلك هو التكلف الطفيف الذي وسم باه عند بعض العلماء قديماً وحديثاً. وقد اتجهت الدراسة لرصد ذلك التكلف من خلال الوقوف على مظاهره، ومحاولة الكشف عن أسبابه، وكان الاعتماد في

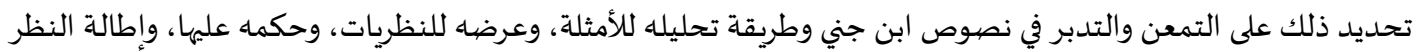
في طرائق تفكيره، وأسس تنظيره، للوصول إلى ما وراء ذلك التفكير من علة أو تبرير، وتتبع المواطن التي ظهر فيها ابن جني متكلفاً أو مبالغاً في الرأي، ودراستها دراسة موضوعية واسية، لا تغض من شأن جهوده وتكشف في الوقت نفسه عن جانب من شخصيته ربما

انعكس على طرحها اللغوي وتبرر موقفا اتخذ تجاهاء في بعض القضيهايا. وقد أبرزت الدراسة التكلف الاشتقاقي بوصفه مظهراً من أكثر مظاهر التكلف حضوراً؛ وقد كان ولوع ابن جني بالاشتقاق سبباً في التزامه والاحتكام إليه، كما رصهدت مظاهر أخرى، من أهمها: محاولة ربط ترتيب حروف اللفظ بمعناه وبالحدث المعبَّر

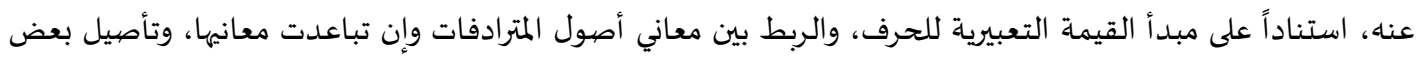
الألفاظ الدخيلة.

أما أكثر أسباب التكلف فتعزى إلى أن ابن جني كان يحاول أن يقلل دائماً من مساحة التباين في اللغة، مع ما تميز به من عقلية تحليلية تعليلية وشخصيته فذة مبدعاة، فهو يحلل المسألة إلى أقصى ما تتحمله ويشرح دقائقها وعللها ويميل إلى الابتكار والإبداع في ثقة واعتد اد، يصحباء إعجاب شديد بلغة العرب، ورغبة في بيان حكمتهم. الكلمات المفتاحية: التكلف اللغوي؛ ابن جني؛ الاشتقاق؛ مناسبة الألفاظ للمعاني.

عُرِف أبو الفتح عثمان بن جني بأنه من أسـاطين التراث العربي وكبار أئمة العربية؛ وقد بلغ هذا الإمام منزلة في علوم العربية فيها

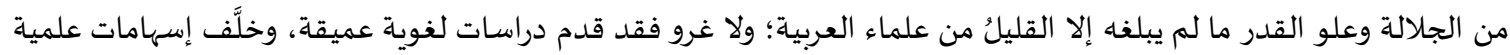
رصينة، وطرائف لغوية عجيبة تنم عن فطنة الرجل ودقة نظره وعلو قدره، تشهد بذلك كتبه وعلى رأسها الخصائص، فبلغ منزلة لم يكد يبلغها أحد غيره. 


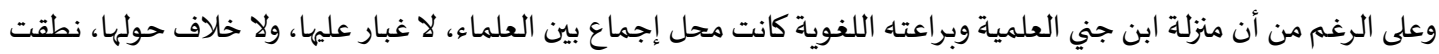

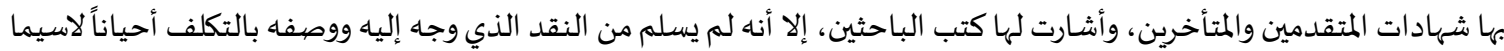

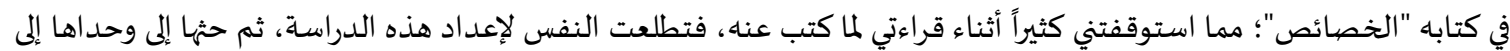

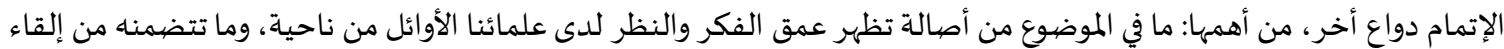

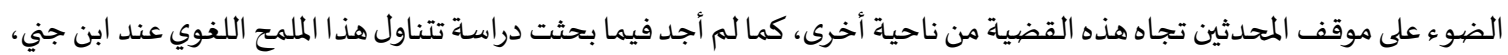
وتهدف إلى الكشف عنده.

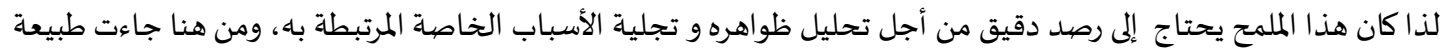

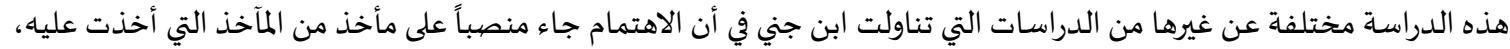

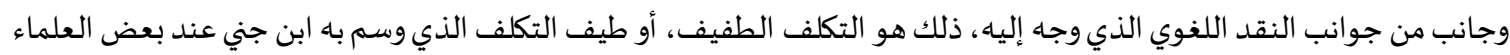

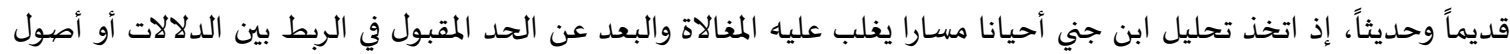

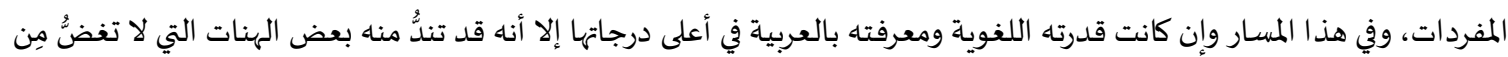
منزلته، ولا تنال من قدره ووفرة علمه. واقتضت طبيعة البحث أن يتكوَّن من المباحث الآتية:

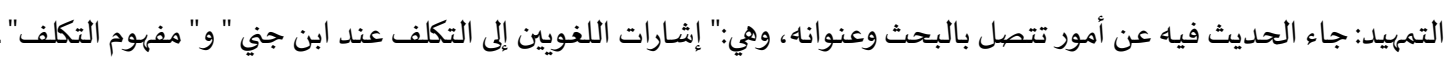

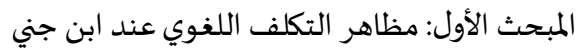

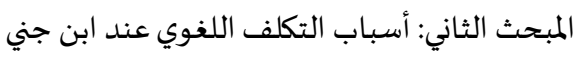
أما منهج هذ البحث فهو المنهج الوصفي القائم على التحليل والتعليل.

التمهيد: اشتهر ابن جني في مجال اللغة أكثر من النحو، عمد إلى إبراز خصائص اللغة وأصولها، وبرع في تفسير الظواهر اللغوية والتعمق

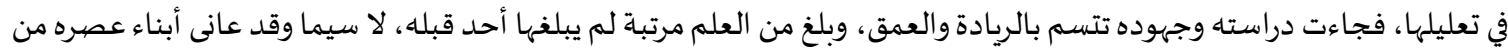

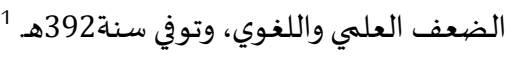
وقد حاز ابن جني على مكانة علمية رفيعة شهد له بها أهل عصره وزمانه وكثير من أهل اللغة والنحو والقائمين على دراسته في

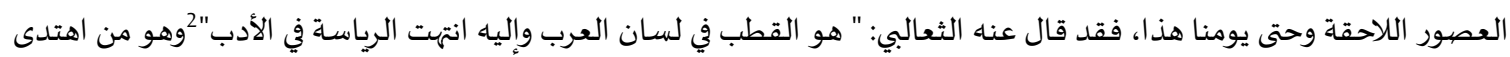

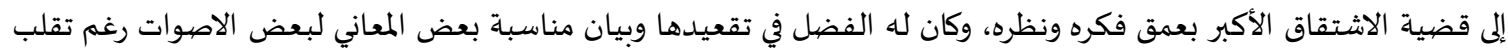

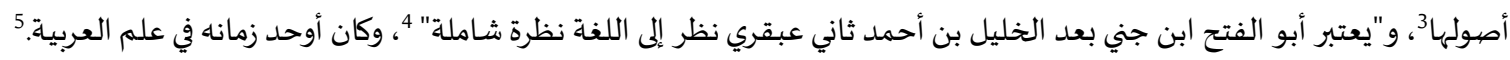

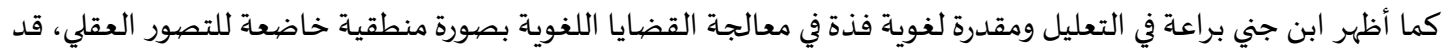

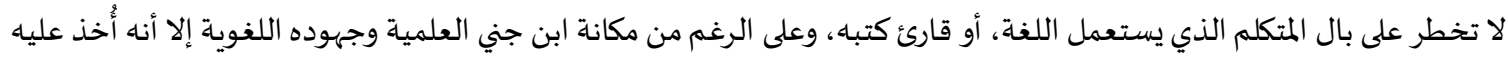

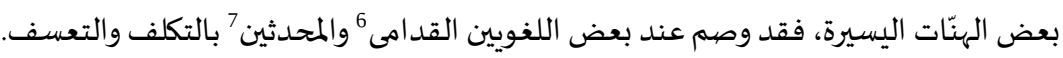

أولاً: إشارات اللغويين إلى التكلف عند ابن جني:

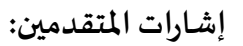

صرح ابن عصفور 669هـ برفضها للاشتقاق الكبير لما فيه من تكلف ابن جني، 8 أما السيوطي

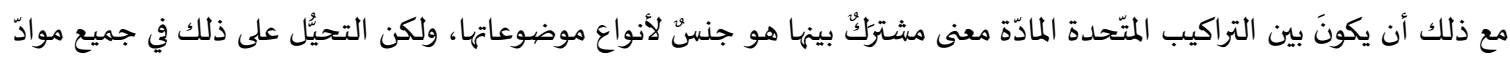

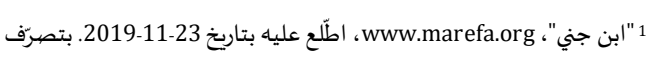

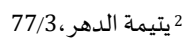
3

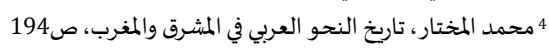
5 الحموي، معجم الأدباء: 232/7

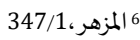
7 وافي، فقه اللغة، ص16138، ألمرهن، أنيس، من أسرار اللغة، ص 68، فقه اللغة وخصائص العربية، ص106، دراسات في فقه اللغة، ص194

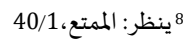


التركيبات كطلبٍ لعنقّاء مُغرب ولم تُحْمل الأوضاعُ البشريّة إلا على فهوم قرببةٍ غير غامضية على البديهة فلذلك إن الاشتقاقات البعيدة جدًا لا يقبلُها المحققون •إشارات المحدثين:

أما بالنسبة لآراء المحدثين فإنهم يتفقون على قدم سبقده، وجلاء عبقريته في علوم العبية، فجلَّ البحوث اللغوية الحديثة تعتمد على آرائه في اللغة، والأصيوات، والتصريف، فقلد كان نسيج وحده في صناعة التصريف، ويعد بحق فيلسوف العربية، وأكبر أئمة النحو بعد الخليل وسيبوياء، وقد بوَّاه الأستاذ أحمد أمين زعامة مدرسة القياس، إلا أن البستاني واني وصفيه بالإغراق فقال:" هو على دقته في

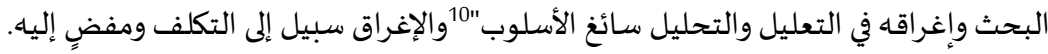

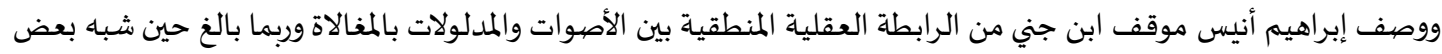

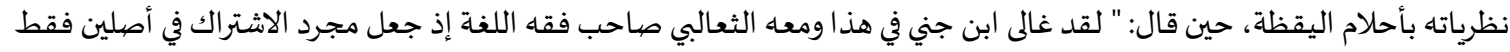

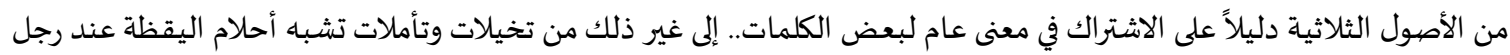

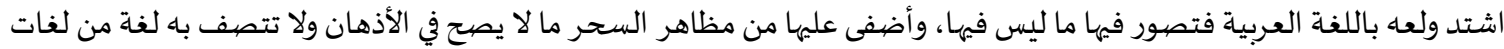
البشر "11 أئت وعبر صببحي الصالح عن ولوعها بالاشتقاق الكبير" أو الأكبر كما يسمياه بقوله: "إن النظرة الأولى إلى صنيع ابن جني في هذه التقاليب

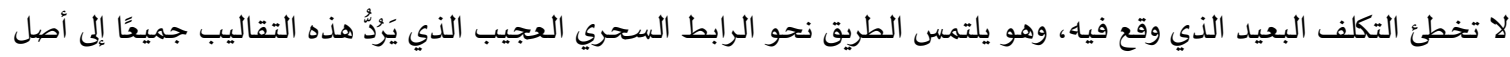
واحد، وإمام منقاد"12 وأكد فكرة التكلف علي وافي حين قال: " وقد بالغ بعضههم في هذا النوع من الاشتقاق، فزعَم أنه يطُّرِد في معظم المواد، والحق أنه

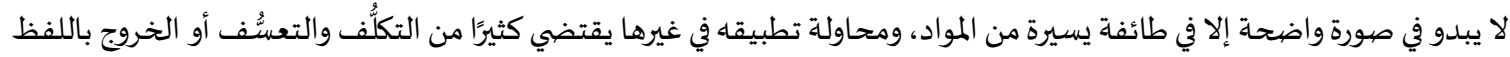

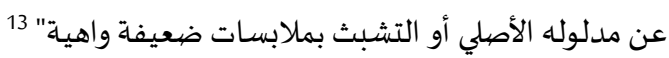
وإلى الطريق نفسه ذهب محمد المبارك إذ نقل عن السابقين أن ابن جني ومن تابعه في تقاليباه قد تكلفوا وتعسفوا في إثبات هذا

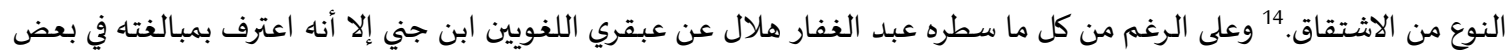

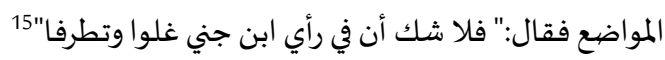
ثانياً: مفهوم التكلف: يظهر مما سبق أن أكثر كلمة كانت تستعمل لوصف مبالغة ابن جني في إثبات فكرته هي كلمة" تكلف" وهو السر وراء اختيارها هنا للتعبير عن هذا الملمح الفكري عند ابن جني، و يجدر بنا قبل الولوج في توصيف مظاهره والبحث عن أسبابها تحديدُ المقصود من التكلف فئف

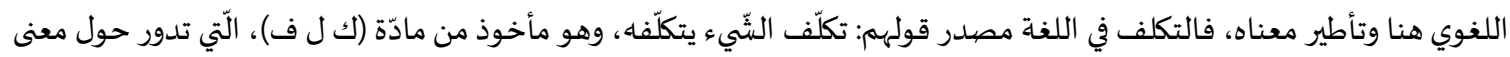

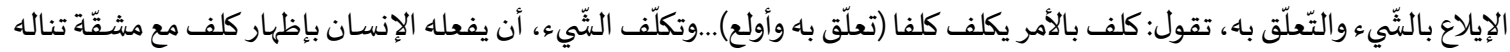

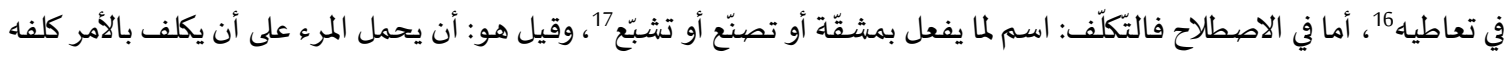
بالأشياء التي يدعو إليها طبعه "18

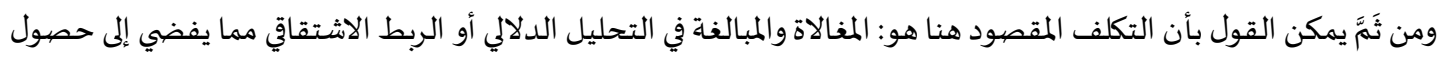
المشقة، ويظهر فياء شيء من التصنع.

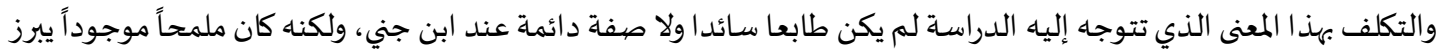
تارة ويختفي تارات، قد يلجأ إليه أبو الفتح لتحقيق أغراض علمية، فيأتي بشواهد لغوية، ويفسر تفسيرات بعيدة، لإثبات فكرته،

\begin{tabular}{|c|}
\hline 9 المزهر:165.164/2 \\
\hline 4 10 دارة المعارف، 420/2 \\
\hline 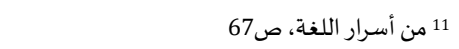 \\
\hline 12 دراسات في فقه اللغة، ص 194 \\
\hline 13 فقه اللغة، ص 141 \\
\hline 14 فقه اللغة، ص106 \\
\hline 15 عبقري اللغويين، ص875 \\
\hline 16 مقاييس اللغة (136/5)، ولسان العرب (9/9307) \\
\hline 17 المفردات، ص.439 \\
\hline 18 المناوي، التوقيف، ص107 \\
\hline
\end{tabular}


والتدليل على صحة نظريته، وليس لبيان قوة ساعده، أو إبراز مقدرته اللغوية، فقد كان يتحلى بقدر كبير من الثقة بالنفس، والاستقلال الفكري والتفرد العلمي.

\section{المبحث الأول:مظاهر التكلف اللغوي عند ابن جني}

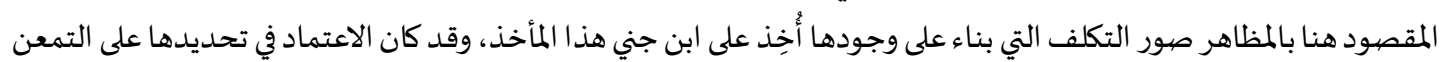

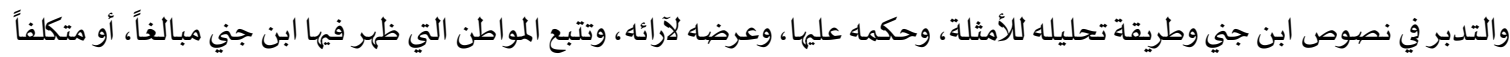
كما وصفه بعضهم.

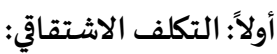
يُعدُ موضوع الاشتقاق من أغزر الموضوعات اهتماماً وأوفرها رعاية في الدرس اللغوي؛ إذ لا يكاد يخلو مدوَّن تخصُُصي في اللغة من مبحث في (الاشتقاق)

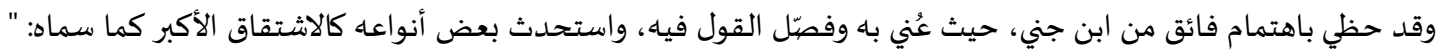

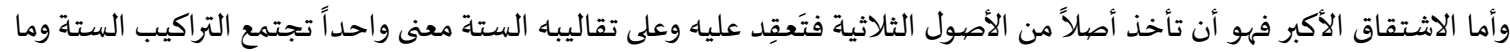

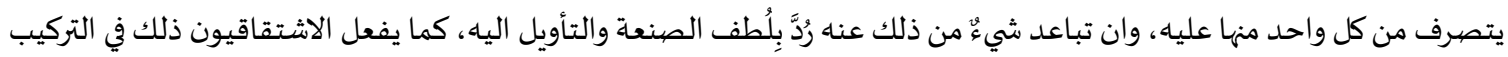
الواحد" 19

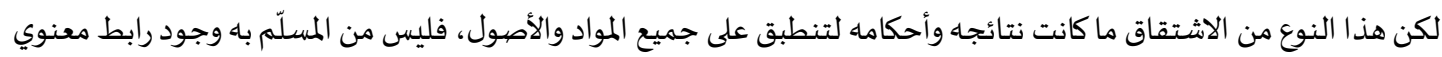

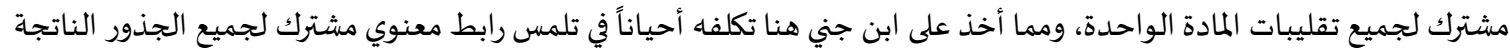

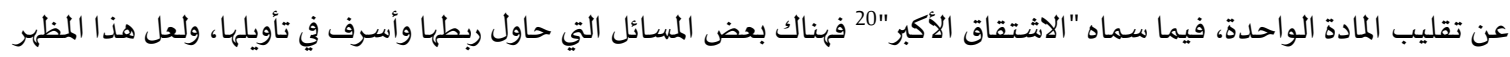

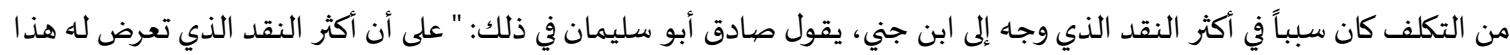

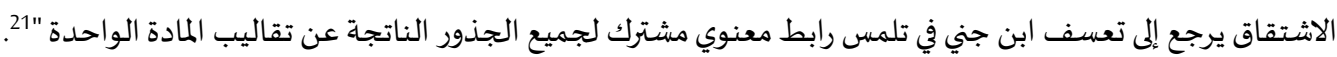

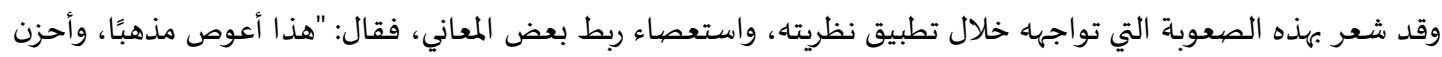

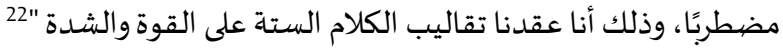

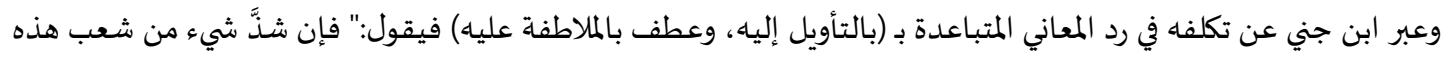

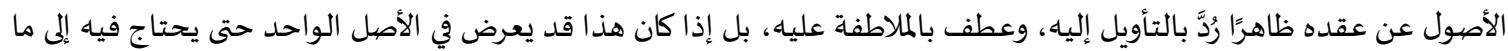

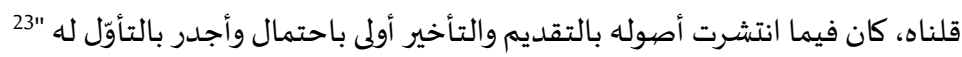

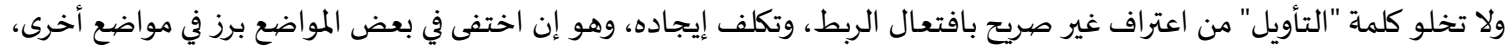

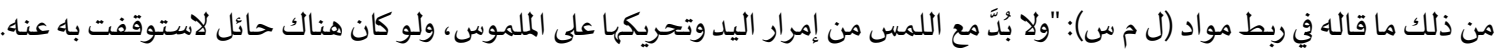

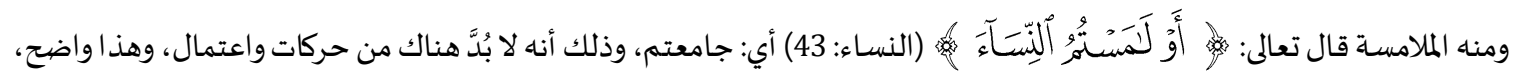

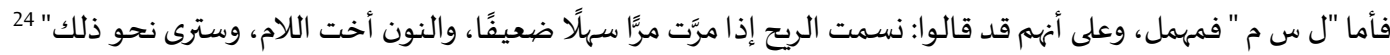

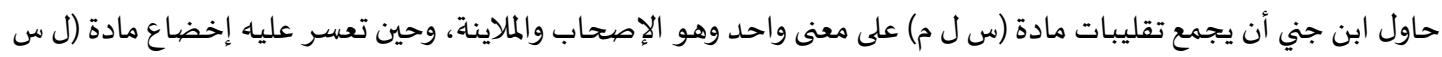

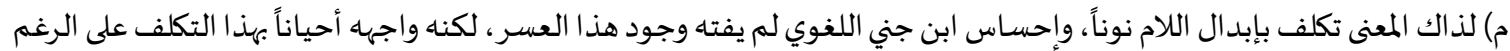
من اعترافاه بصعوبة ما يدعو إليه.

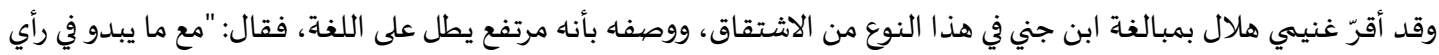

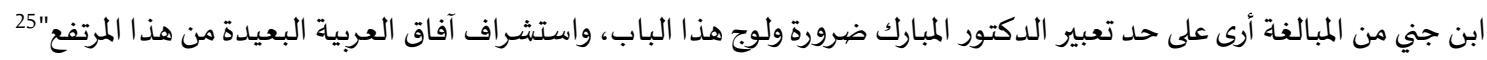

\begin{tabular}{|c|}
\hline 19 الخصائص:136/2 \\
\hline 20 وهو" الاشتقاق الكبير" عند غيره \\
\hline أنواع الاشتقاق في العربية، ص 140 \\
\hline 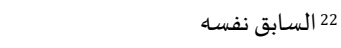 \\
\hline 23 الخصائص:139/2 \\
\hline 140/2 السـابق \\
\hline
\end{tabular}

25 عبقري اللغويين، 849، وينظر: المبارك، فقه اللغة وخصائص العربية، ص88 
وقد وقع ابن جني في هذا النوع من التكلف في بعض المسائل في باب آخر وهو: " تلاقي المعاني على اختلاف الأصول والمباني" حيث

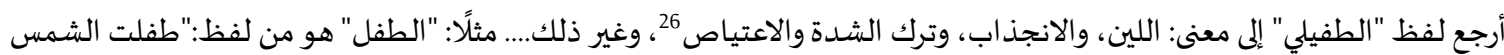

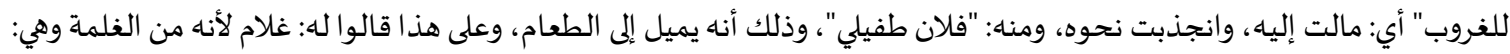
اللين، وضعفة العصمة، وكذلك قالوا: "جارية" فهي: "فاعلة" من: جرى الماء، وغيره...وذلك أن الطفل والصببي والغلام والجارية ليس لهمه

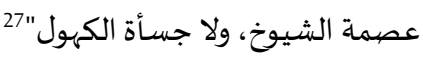

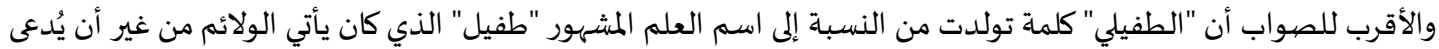

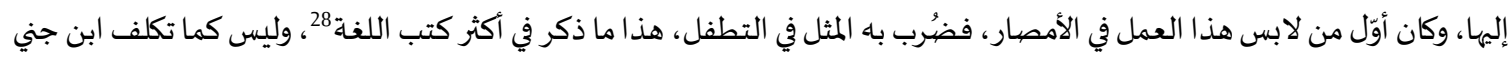
في بيان حقيقة معنى اشتقاق الطفيلي.

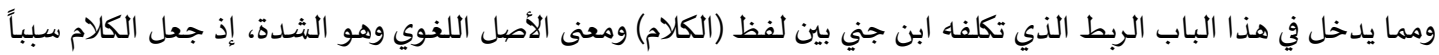

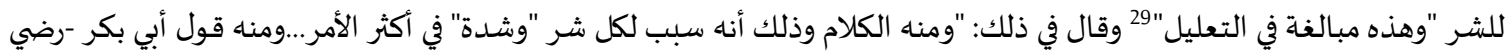
الله عنه- في لسانه: "هذا أوردني الموارد" ويعلق السامرائي على ربط ابن جني لتقليبات (ك ل م) بأنه:" تكلف ظاهر إذ يمكن أن يعلل بعكس هذا الأمر تماماً" 31

ثانياً: خلق مناسبة لترتيب الحروف أو تجاورها:

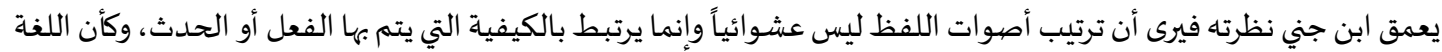

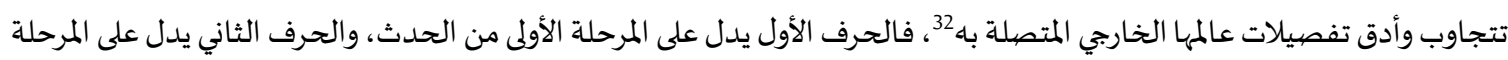

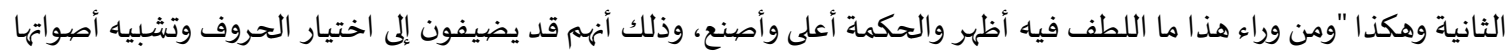

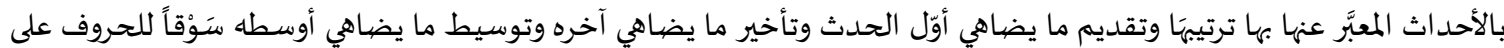

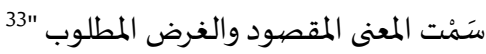

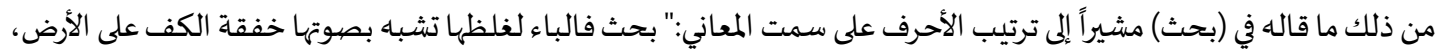

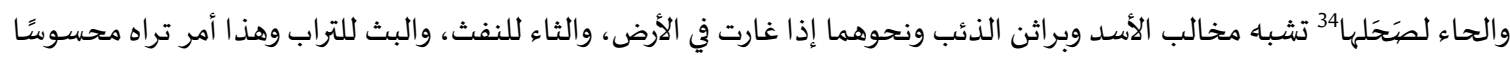

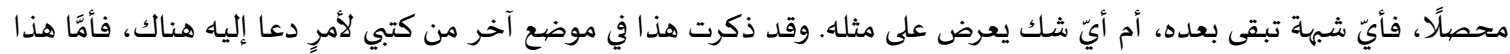

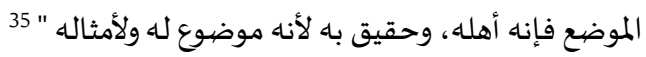

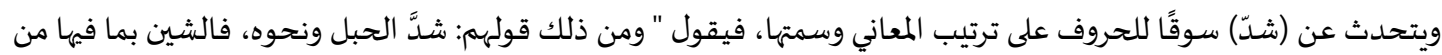

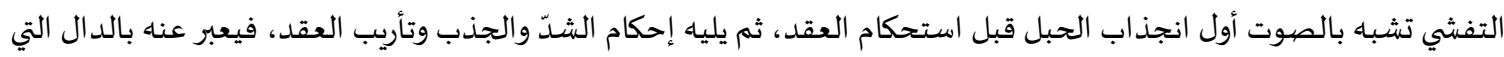

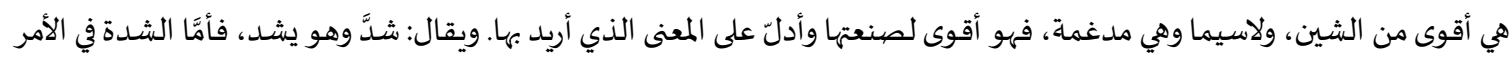

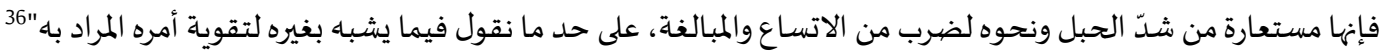

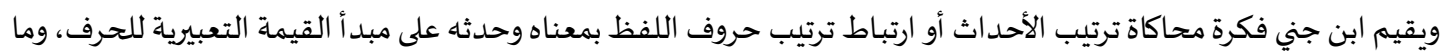

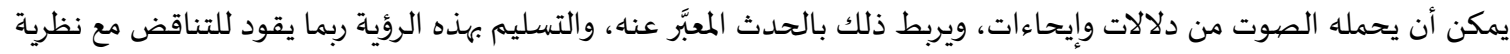

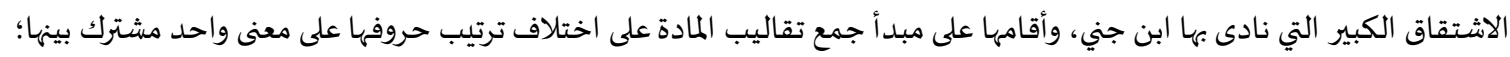

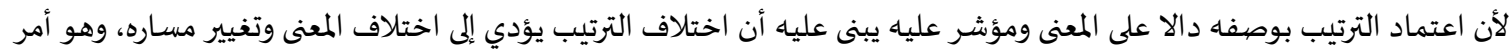
يثقل كاهل اللغة.

120/2 26 27 الخصائص:21/21 الخصانص،

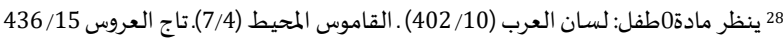
29 السامرائي، ابن جني اللغوي، ص207 إنسان

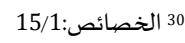

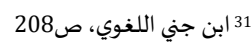
32 سائدة العيص، الوجهة الاجتماعية عند ابن جني في الخصائص، ص89 (بتصرف) 133 السابق:164/2 (34 الصحل: البحة في الصوت. الخصائص:163/2 الخدل: 36 السابق:165/2 الخصائ:1635 


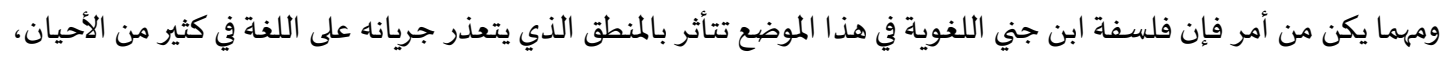

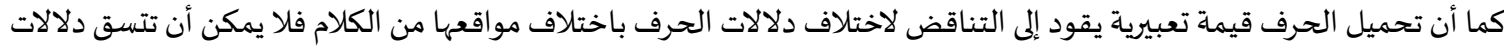
حرف مع كل الألفاظ التي وقع فيها.

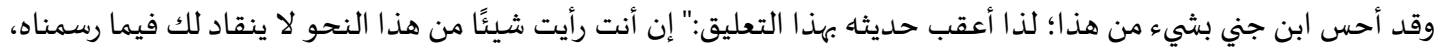

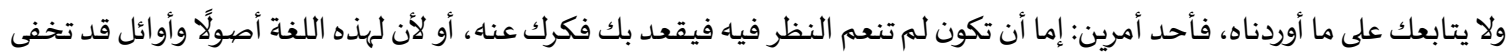

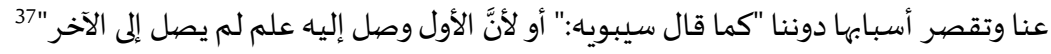

ثالثاً: تكلف الربط بين معاني أصول المترادفات وإن تباعدت بمعنى واحد يجمعها:

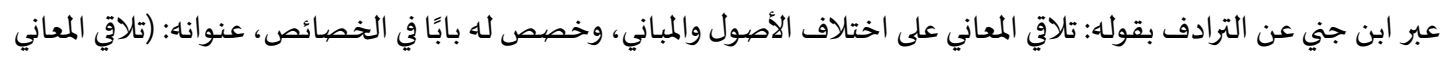

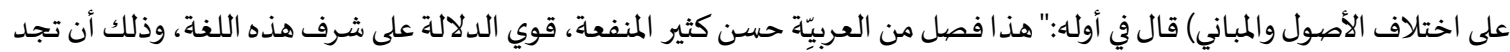

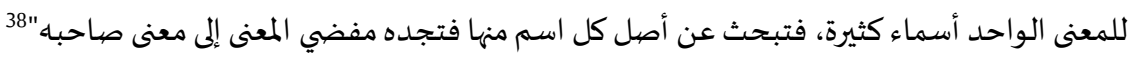

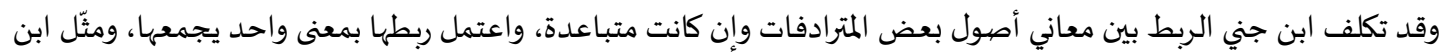

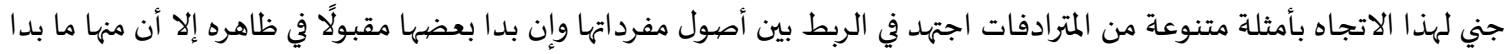

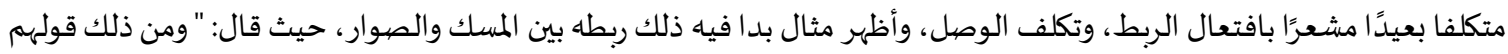
للقطعة من المسك: "الصهوار" قال الأعشى: إذا تقوم يضوع المسك أصورة ... والعنبر الورد من أرداهها شمل

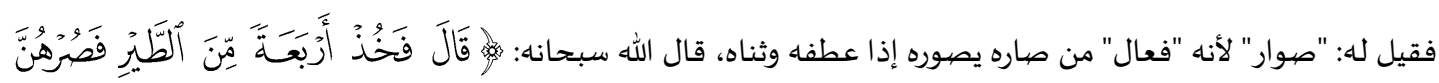

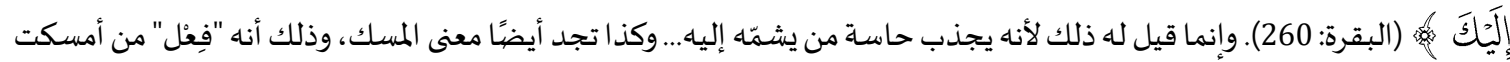

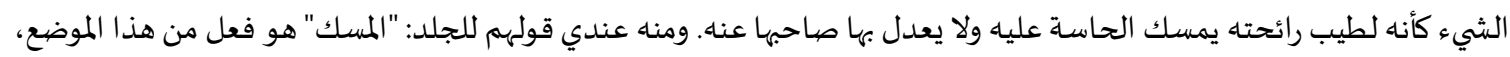

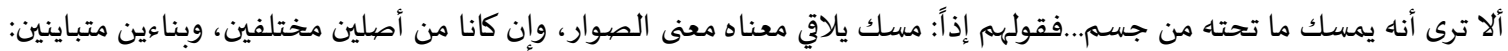

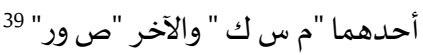

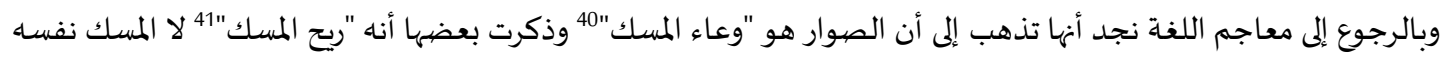

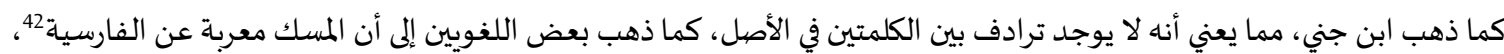

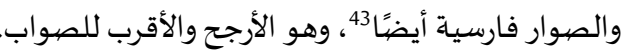

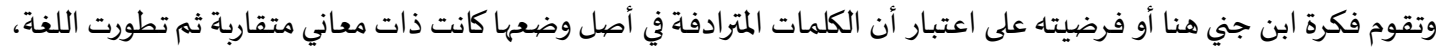

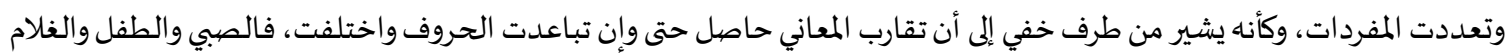

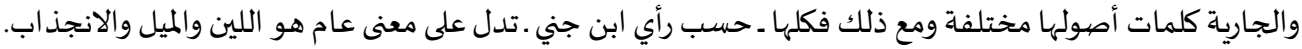

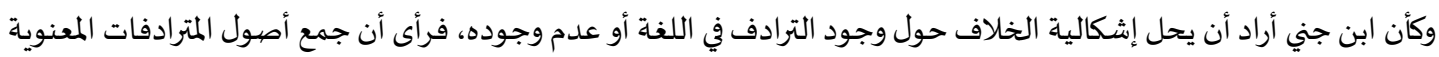
برابط معنوي ينفي عن اللغة فكرة الفوضى وكل ما ينافي الشرف والحكمة.

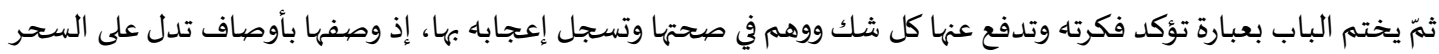

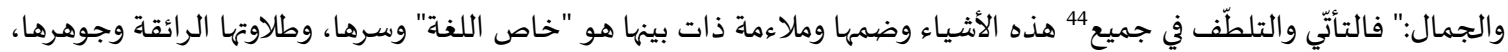

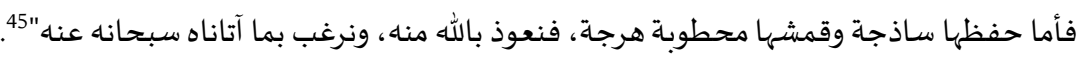

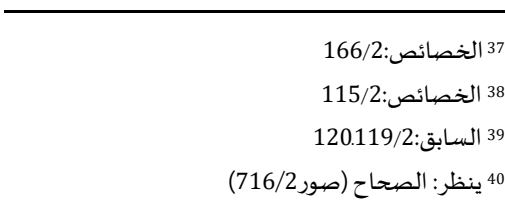
أساء

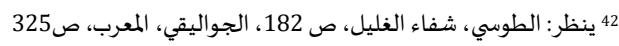
(476/4 لسان العرب (صور) 44 لعلها "جمع" وهو أدق وأنسب للسيان العرب 453 45 الخصائص: $127 / 2$ 
رابعاً: الربط الدلالي بين كلمتين مع اختلاف الحرفين والثلاثة: تقوم فلسفة ابن جني على أن التقارب الصوتي في الأصول بين لفظين يؤدي إلى تقارب معانهيا أو أن تقارب المعاني في لفظين يقود إلى تقارب حروفها صوتيا وهو ما عبر عنه بقوله: "وهو أن تتقارب الحروف لتقارب المعاني"

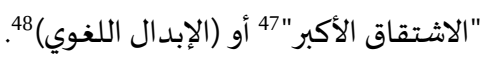

ولم يقف حديث ابن جني في الاشتقاق الأكبر عند الألفاظ التي يقتصر فيها الاختلاف على الصهوت الواحد الإد كما في (أزّ) و(هزّ)، وإنما تجاوزه لادّعاء التقارب بين ألفاظ اختلفت كل أصولها الثلاثة، فيقول:" وتجاوزوا ذلك إلى أن ضارعوا بالأصهول الثلاثة: الفاء والعين

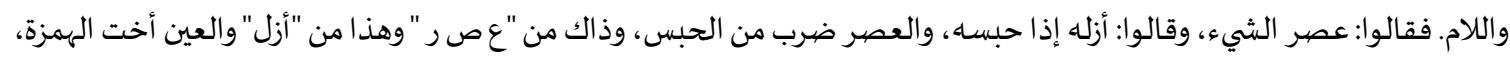

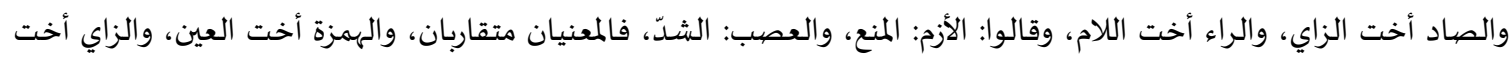

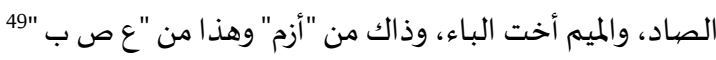

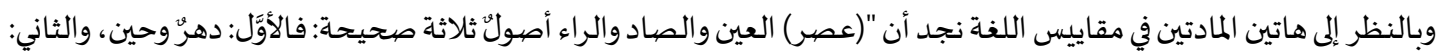

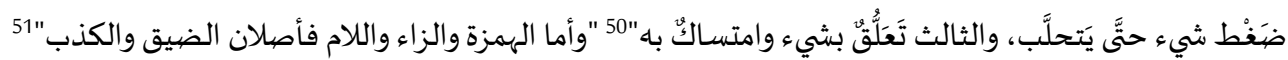

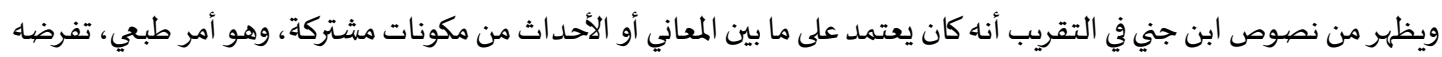

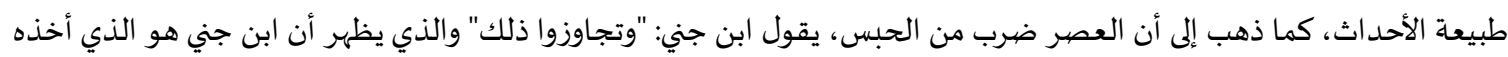

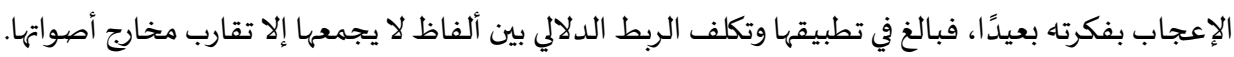

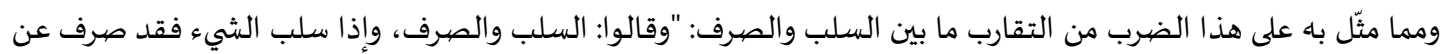

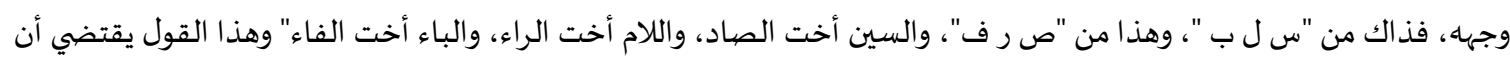

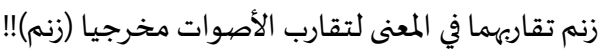

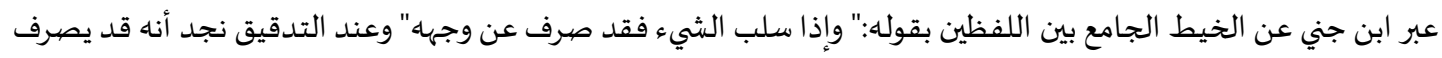

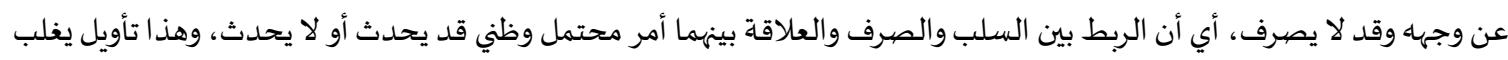

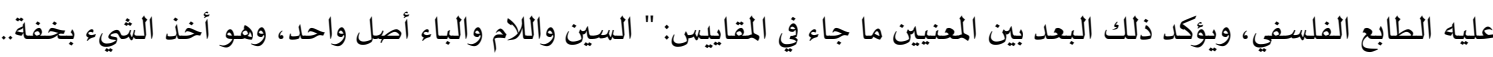

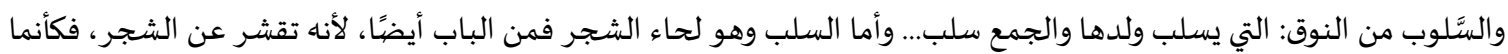
قد سلبته" 52 "الصاد والراء والفاء معظم بابه يدل على رجع الشيء...ومعنى الصرف عندنا أنه شيء صرف إلى شيء، كأن الدينار صرف إلى ...

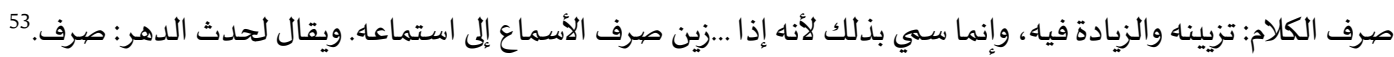

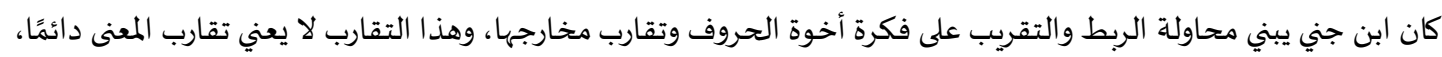
فقد يحدث ولكن لا يعمم، والتزم في شرح الأمثلة الاتكاء على نقطة وهذا الحرف أخت للحرف، وتكرارها في كل مرة، وكأنها السبب وراء ذلك التقارب أو الإيمان باء.

وقد يحدث تكلف التقارب الدلالي بين أكثر من كلمة كما مثل بـ جلف وجنف وجرف، فذهب إلى أن:" الراء أخت اللام والعملان

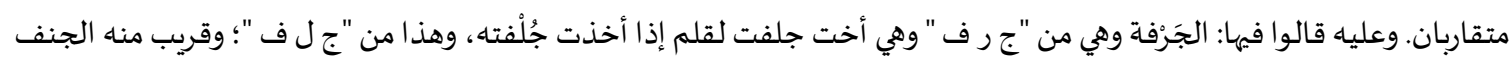

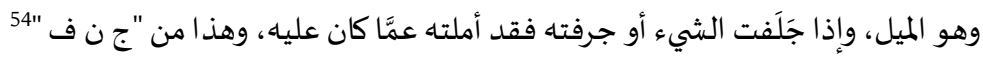

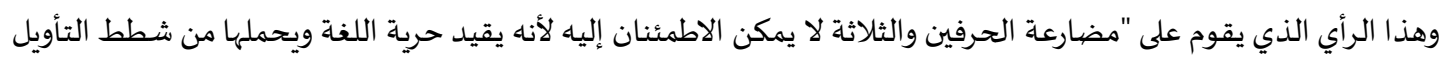

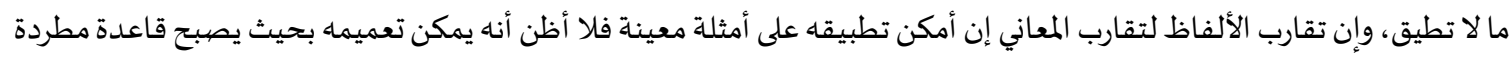

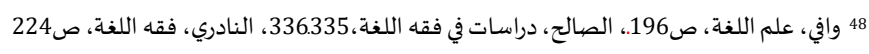
49 الخصائص:154/2 50 مقاييس اللغة: $540 / 4$ 51 السابق، $50 / 1$ 52 مقاييس اللغة:92/3 53 مقاييس اللغة:543/343 مقايس اللفة 54

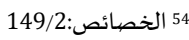
55 أنواع الاشتقاق، ص144 الخدائ154 
خامساً: الحكم على ألفاظ دخيلة بأنها عربية أصيلة:

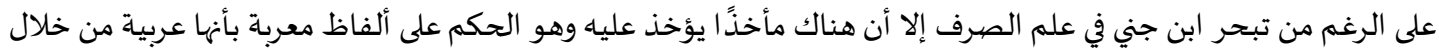

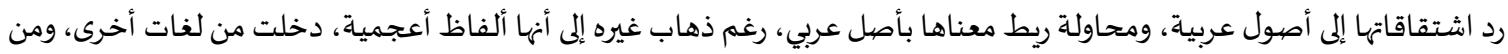

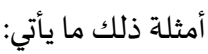

النبراس: وهو معرب معناه المصباح 56، وقد أصلّه ابن جني، وأدرجه ابن جني تحت زيادة النون، فقال فيه: " وأما نون نبراس فقد

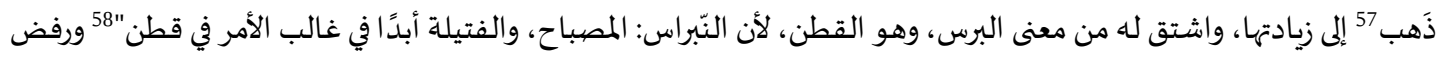

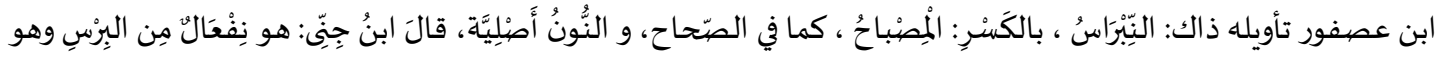

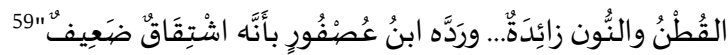

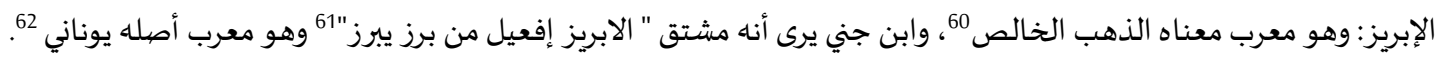

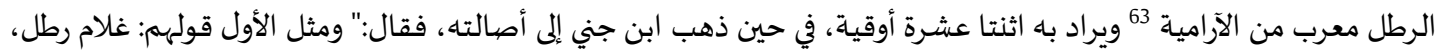

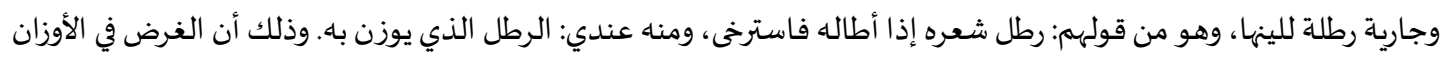

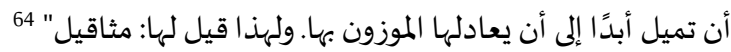

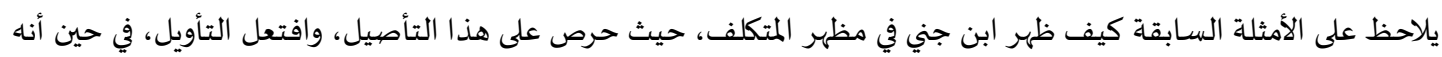
بدا بعيدًا غير مسوغ، وظهر معه حمل اللفظ على وجه غير متقبل. سادساً: الاعتقاد بأن المناسبة بين أصوات الألفاظ ومعانهيا ذاتية مطردة:

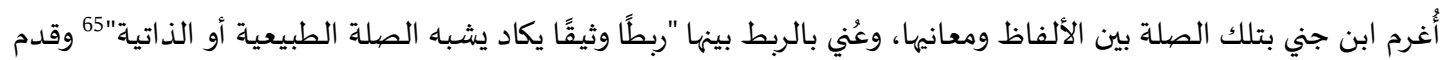

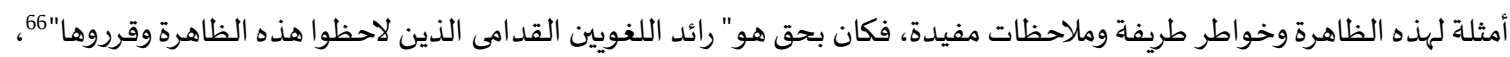

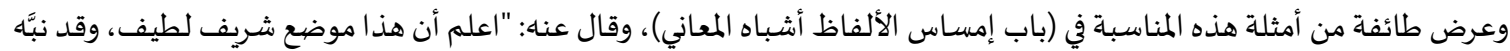

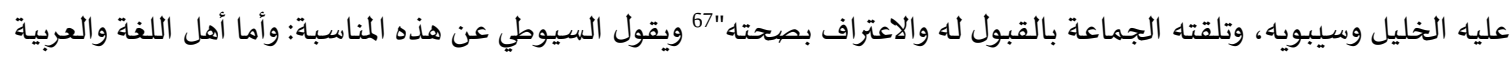
فقد كادوا يطبقون على ثبوت المناسبة بين الألفاظ والمعاني 68.

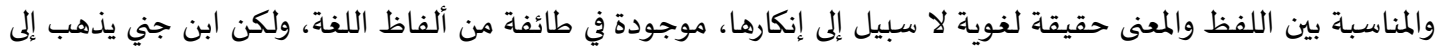

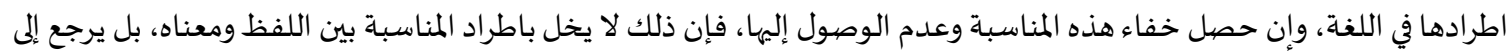

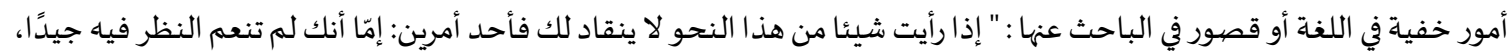

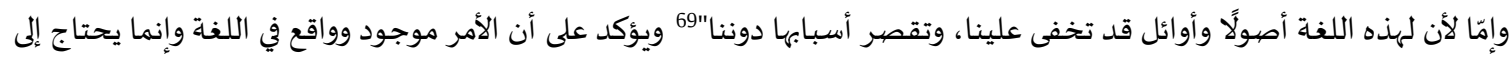

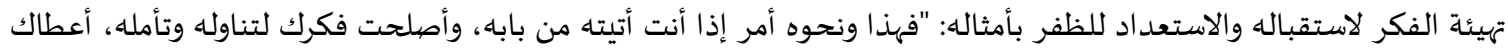

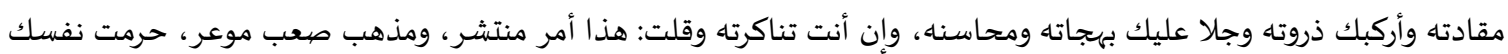
لذته، وسددت عليها باب الحظوة به"

$$
\begin{aligned}
& 56 \text { ينظر: تفسير الألفاظ الدخيلة، ص73، المعرب، ص } 340 \\
& 57 \text { هكذا جاءت بفتح الذال في الكتاب. }
\end{aligned}
$$

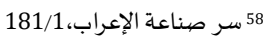

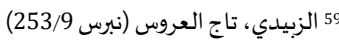

$$
\begin{aligned}
& 60 \text { الجواليقي، المعرب، ص25 العروس (نربس } \\
& 61 \text { الخصائص:125/2 الجواليت المعربا صائ } \\
& 62 \text { تفسير الألفاظ الدخيلة، ص1/251 }
\end{aligned}
$$

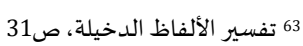

$$
\begin{aligned}
& \text { } 64 \text { السابق:122/2 } \\
& 65 \text { إبراهيم أنيس، دلالة الألفاظ، ص } 60
\end{aligned}
$$

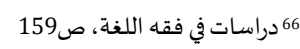

$$
\begin{aligned}
& \text { 167 الخصائص، } 154 / 2 \\
& \text { 31/1، } 68 \text { المزهر، } \\
& \text { 69 الخصائص، } 613 \text { المزصر، } \\
& \text { 70 السابق، 164/2 }
\end{aligned}
$$


وافتراض وجود المناسبة في ألفاظ اللغة كلها أمر مبالغ فياه، لأن في اللغة كثيرًا من الألفاظ الموضوعة للمعنويات كالحلم والعقل وأسماء الأجناس كالثعلب وغيرها لا تظهر فهيا هذه المناسبة بين الأصوات والمعاني؛ لأن اللغة في أصل وضيعها كانت فئ للأصوات

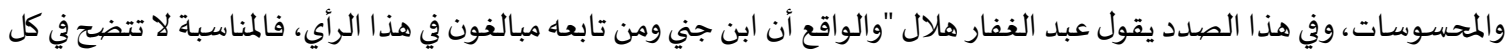

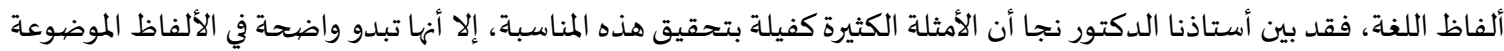

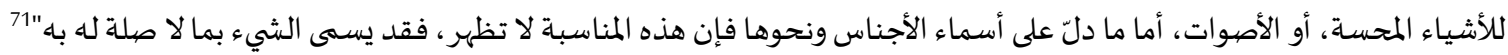

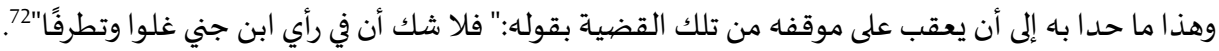

سابعاً: تلمس الألفاظ العامة للتعبير عن الرو ابط المعنوية:

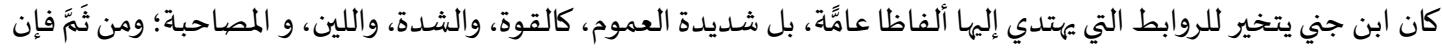

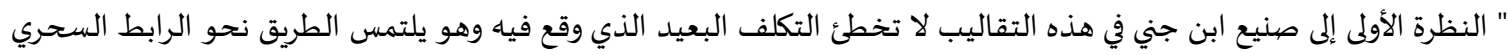

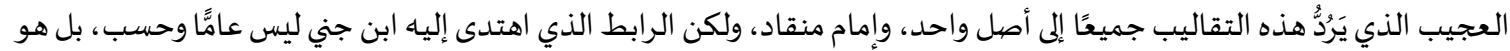

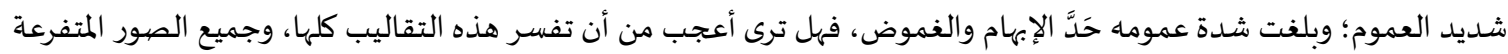

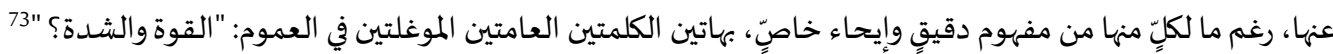
وهكذا رافق ذلك التكلف شيء من العموم، يسوغه، ويكتسي باه، فيظهر مقبولا سائغا، تتحمله اللغة، ولاهي يرفضيه العقل.

\section{ثامناً: تعميم نتائج أفكاره ونظرياته على المواد والأصهول:}

إن تعميم الفكرة على اللغة كلها، وعدَّها قاعدة مطردة هو جزء من فكرة المبالغة، فقد تكون الفكرة مستساغة في بعض الأمثلة

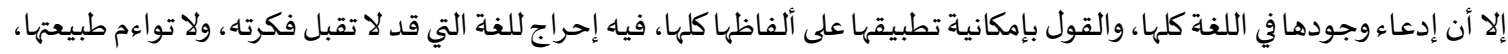

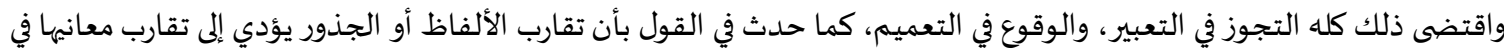
جذرين أو لفظين. وقد يقول قائل إن ابن جني لم يزعم بإمكانية تطبيقها على اللغة كلها، وهذا صحيح لكناه ما يلبث أن يؤكد على أن ذلك يحتاج

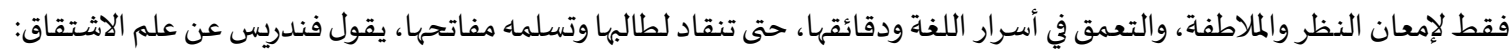

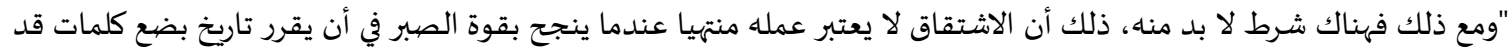

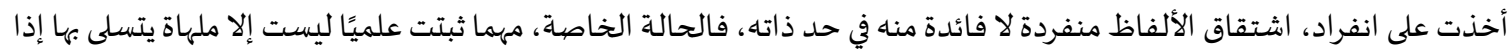
لم يستخرج منها مبدأ عام يستطاع تطبيقه على حالات أخرى، ونحن نعلم أنه يوجد من بين الاشتقاقات حالات كثيرة لا تؤدي إلى نتائج

\section{المبحث الثاني: أسباب التكلف اللغوي عند ابن جني} إن "من طبيعة العقل البشري أن يتساءل عن الأسباب الكامنة وراء أية ظاهرة مهما يكن نوعها، فيبحث عن تفسيرها بإخضاعها

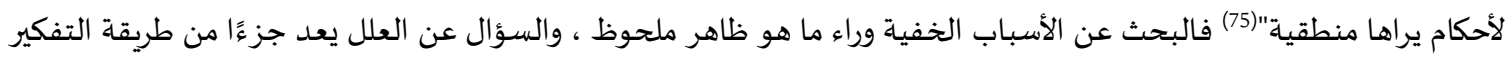

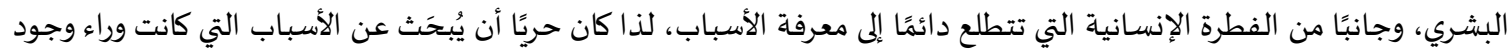

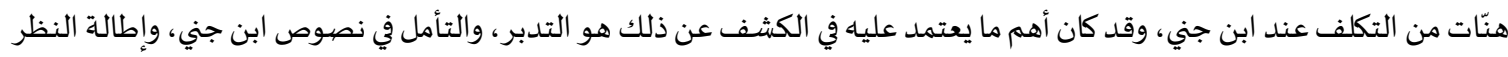

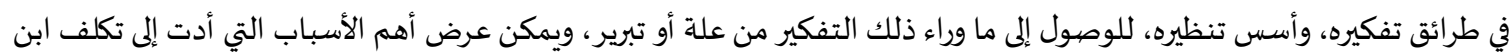
جني ومبالغتاه من وجهة نظر الباحث وفق العناصر الآتية:

71 71

السابق نفسـه.

201 73راسات في فقه اللغة 243

74 اللغة، ص 249

75 بلقاسم بلعرج، ظاهرة تعليل الألفاظ، مجلة الدراسات اللغوية، 1 


\section{فكرة ارتباط أصهوات الألفاظ بمعانيها}

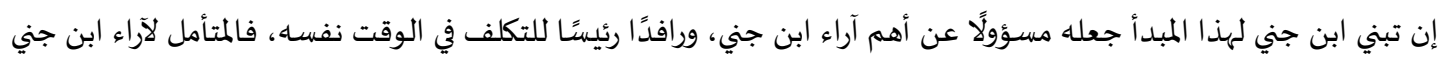

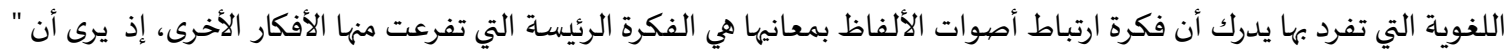

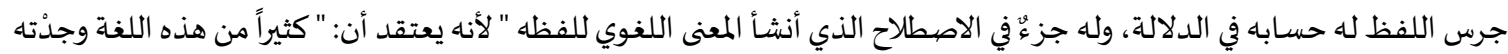

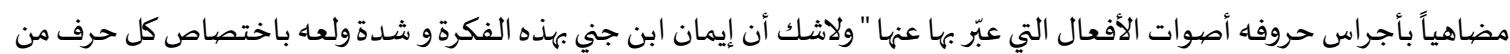

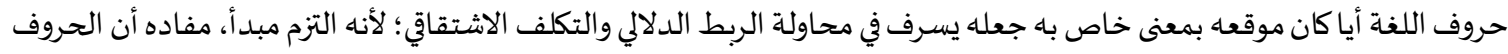

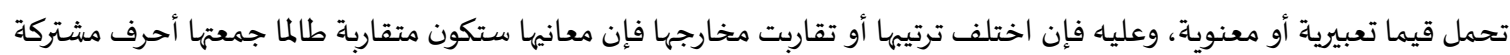

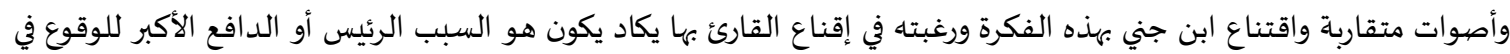

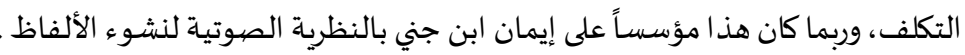

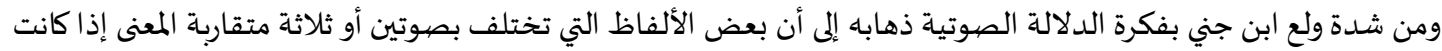

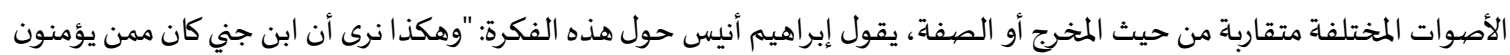

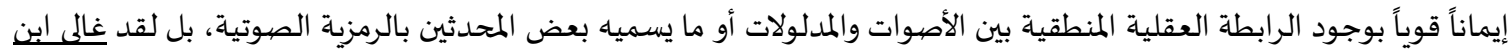

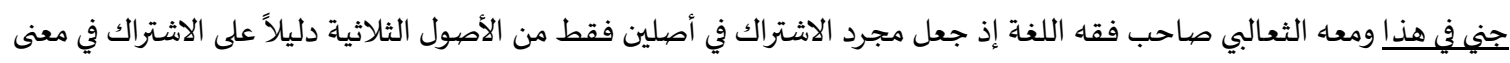

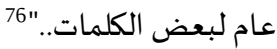

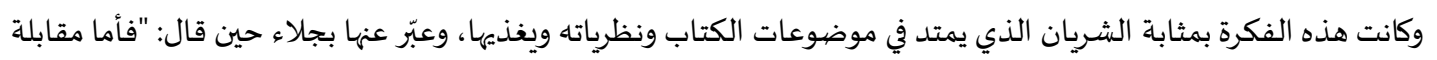

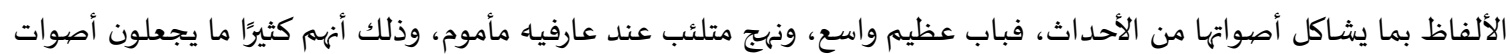

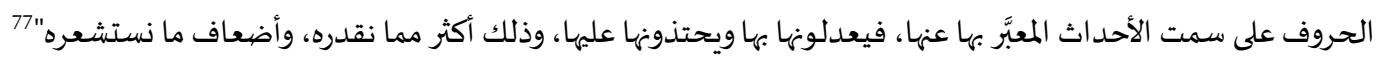
ميل ابن جني إلى التعليل

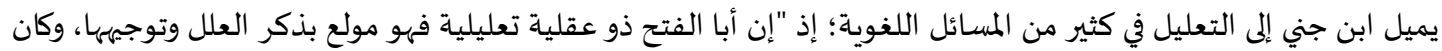

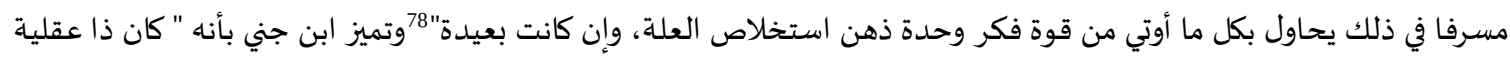

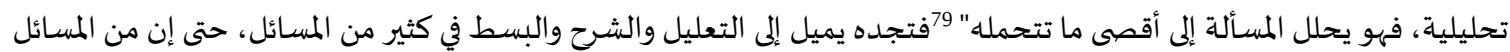
ما لم يذكر في باب واحد، وإنما يذكر في أماكن متفرقة في الكتاب، ويشير المالي إلى إلى ذلك.

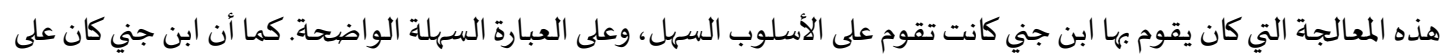

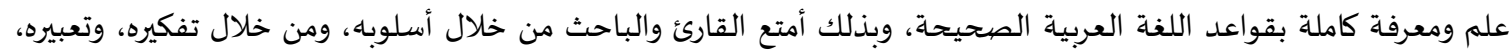

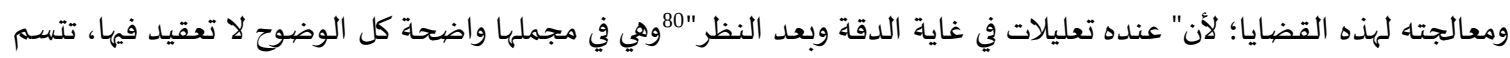
بالموضوعية، والقرب من واقع اللغة إلا فيما ندر.

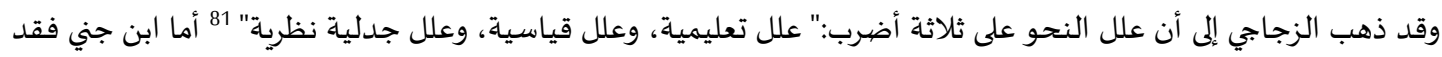

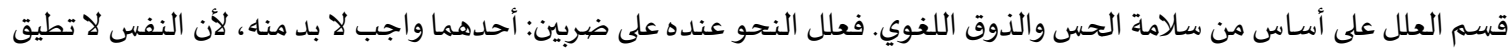

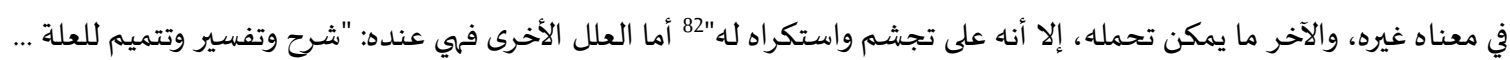

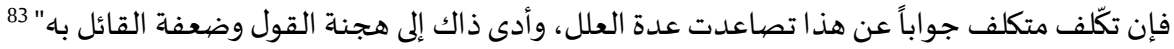

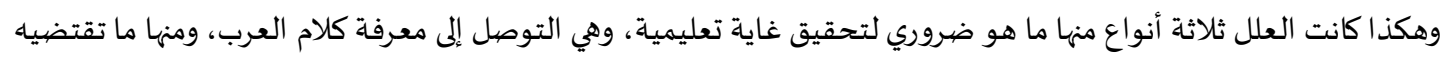

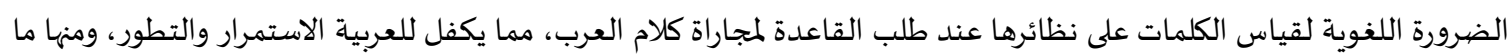
يتصل بالجدل والنظر وإظهار البراعة في البحث والاستقصاء، ويدل على تمكنه من زمام اللغة، وتمكنه من أساليب البحث وطرائق

\begin{tabular}{|c|}
\hline 76 من أسرار اللغة، ص67 \\
\hline 177 الخصائص، 154/2 \\
\hline 78 ابن جني النحوي، ص 207 \\
\hline 79 السابق، ص 212 \\
\hline 80 ابن جني النحوي، ص 208 \\
\hline 81 الزجاجي، الإيضاح في علل النحو، ص 64 \\
\hline 82 الخصاص:137/1 \\
\hline 233 السابق:229/1 \\
\hline
\end{tabular}


النقاش، ولعل هذا النوع الأخير هو ما حذا بابن جني نحو هذا النوع من التكلف؛ لأنه يندفع للوقوع في علل تبدو فيما ندر واهية " فتراه

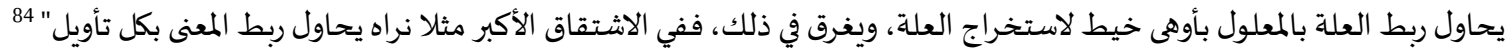

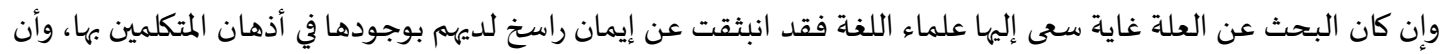

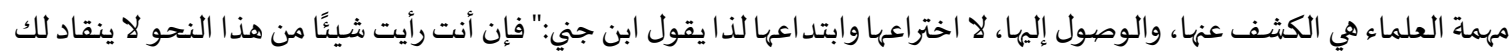

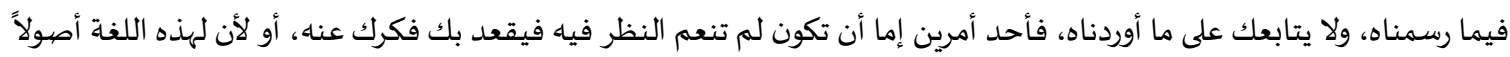

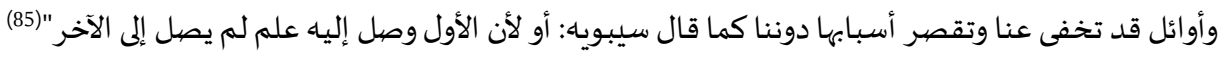

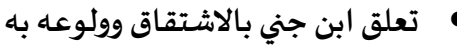

وقد تعلق ابن جني بالاشتقاق في كثير من المواضع واحتكم إليه في توضيح بعض المششاكل، لكي يحدد أصل اللفظين، ويميز بين الأصل والفرع وأيهما اشتق من الآخر.

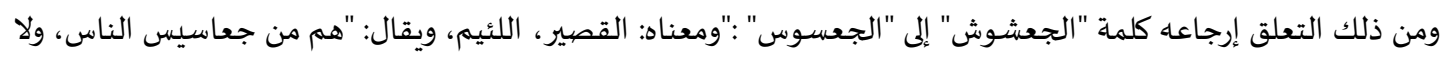

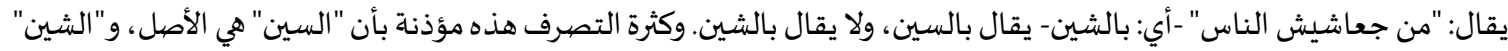

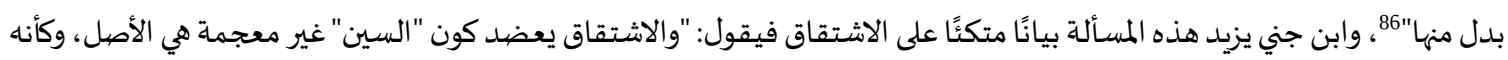

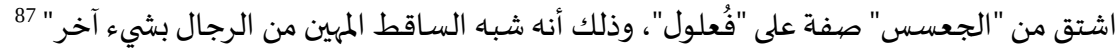

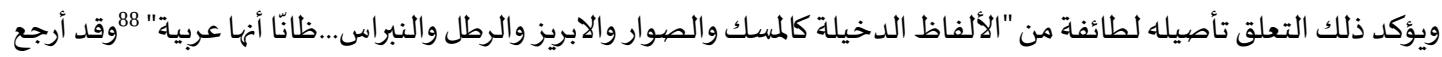

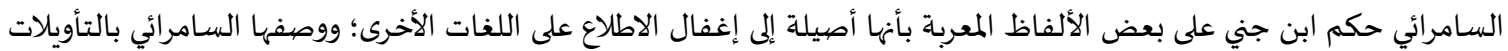

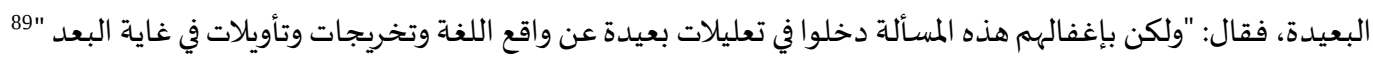

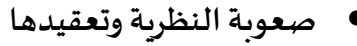

أسهمت غرابة الفكرة التي يدعو إلها وصعوبة تطبيقها على اللغة،، واحتياجها أحيانًا إلى شيء من التكلف والاحتيال في وجود طيف

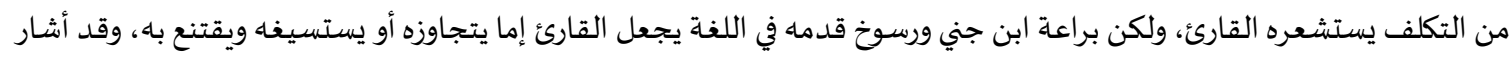

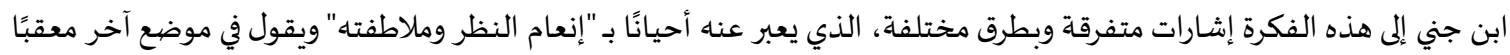

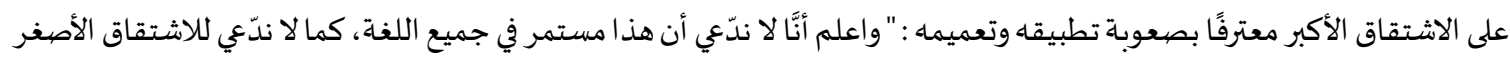

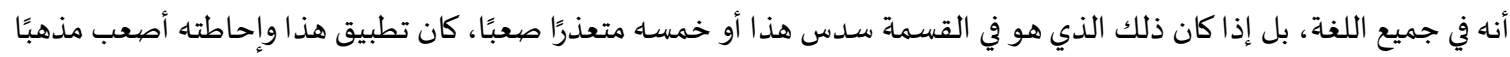

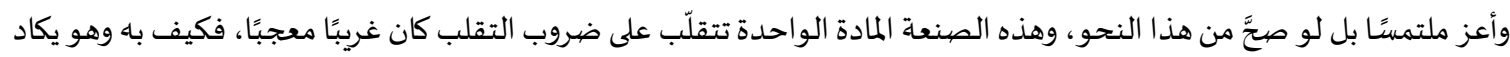

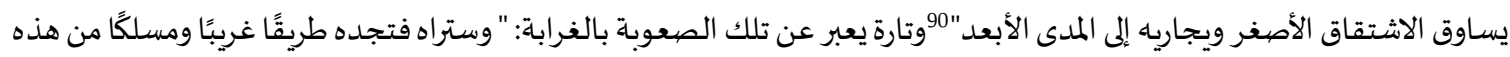

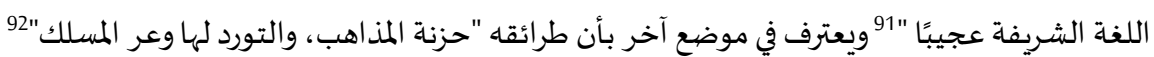

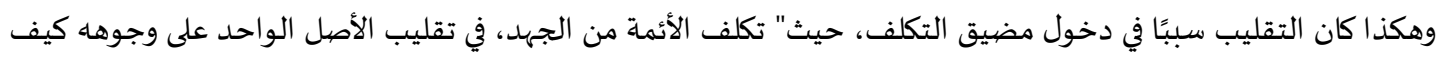

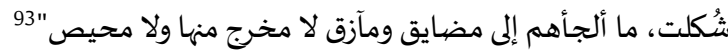

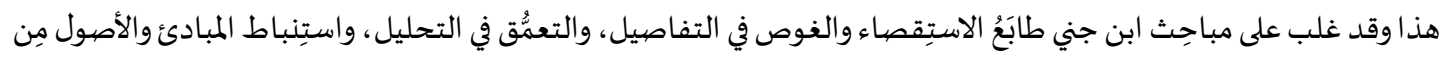
الجزئيات.

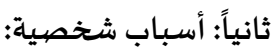
كان لابن جني سمات تميز شخصيته عن غيره من العلماء، ولعلها أسهمت بصورة مباشرة، أو غير مباشرة في وجود هذا الطيف من التكلف، أو لنقل تغذيته، ومن أهم هذه السمات:

السـامرائي، ص 207

85 الخصائص، 164/2.

86 الخصائص، 86/2 87 السابق، 86/2 88 ابن جني النحوي، ص212

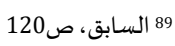
90 الخصيائص:141.140 91 الخصائص: 5/1 92 93 الزعبلاوي، دراسات في النحو، ص 554 


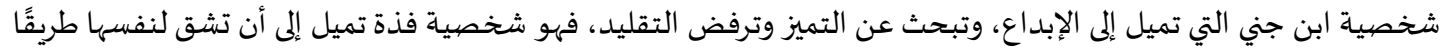

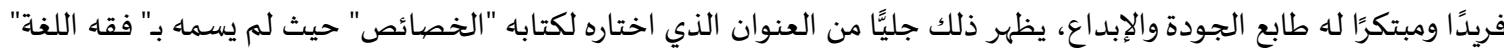

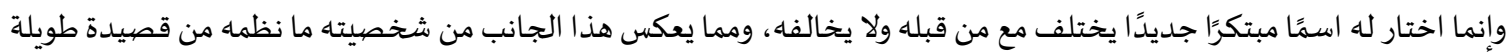

$$
\begin{aligned}
& \text { فإن أُصبح بلانسَبٍ فعِلِي في الورَى نَسَبِي } \\
& \text { على أنّي أؤولُ إلى قروحٍ سـادةٍ نُجُبِ } \\
& \text { قياصِرة إذا نطَقُوا أرمَّ الدهرُذو الخطبِ } \\
& \text { أُولالَكَ دعا النبيُّ لهم كفَى شرفًا دعاءُ نَبي }
\end{aligned}
$$

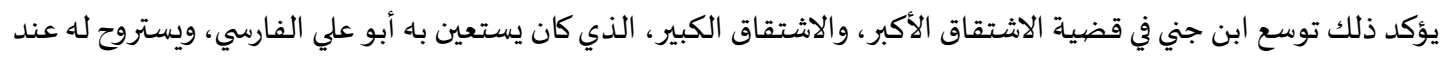

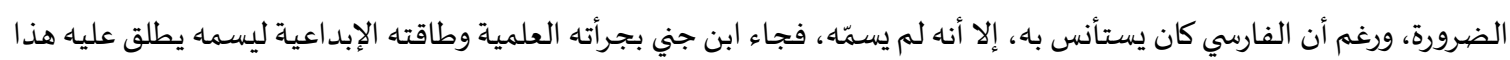

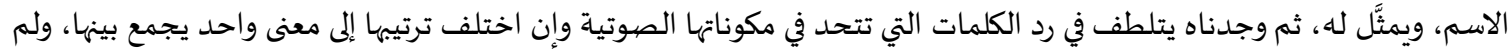
يزعم أن ذلك مطرد في جميع اللغة.

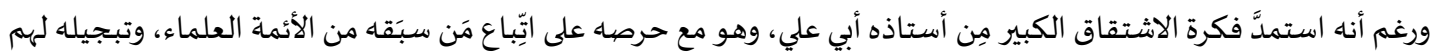

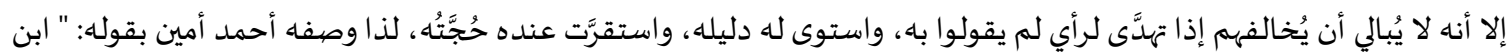

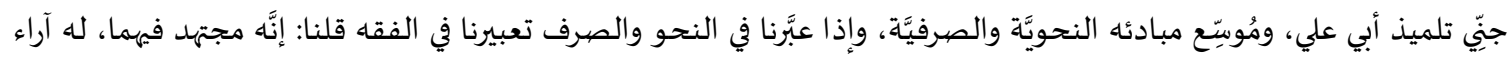

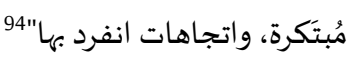

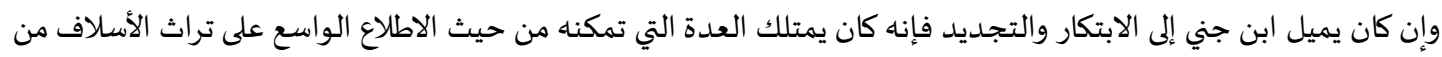

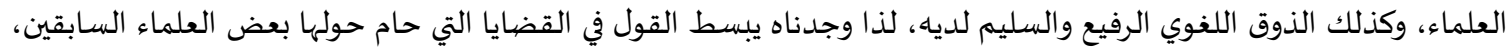

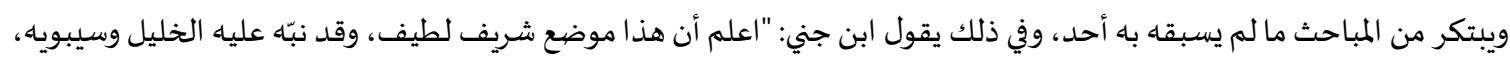

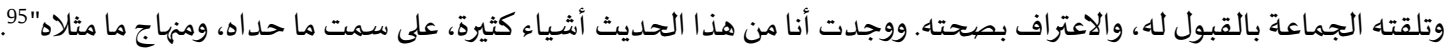

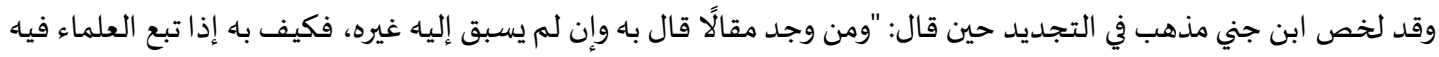
وتلاهم على تمثيل معانيه"

\section{مالإيمان العميق والقناعة التامة بأفكاره التي يدعو إليها}

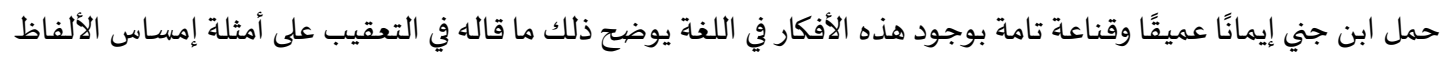

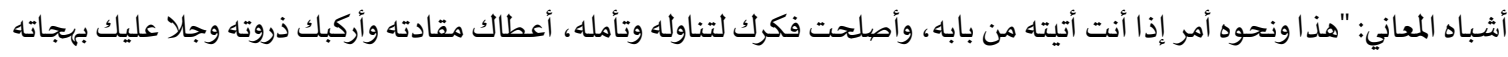

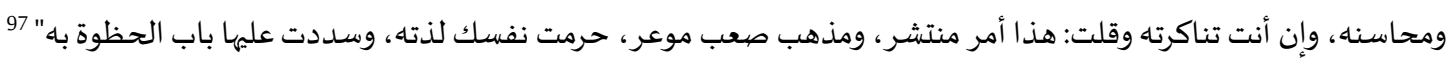

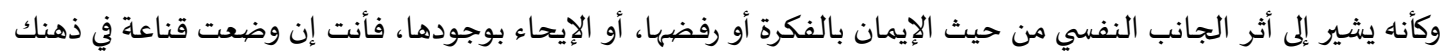

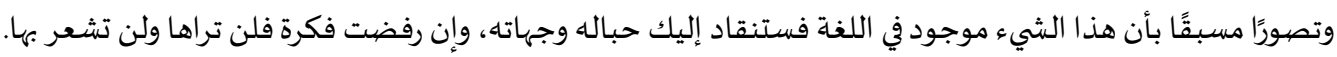
وإن كان ذلك كذلك فأولى الناس بحصيول هذا هو ابن جني نفساه، إذ إن إيمانه بفكرته واعتقاده بها دفعادها إلى رؤية آثارها في اللغة،

وإمكانية تطبيقها على اللغة، وانسجامها معها.

وكأن كلامه يحمل إشارة إلى أن القضية ليست حقيقة وواقعا في اللغة بقدر ماهي تصهور واعتقاد يلقى على اللغة.

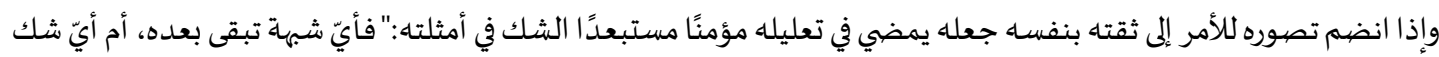

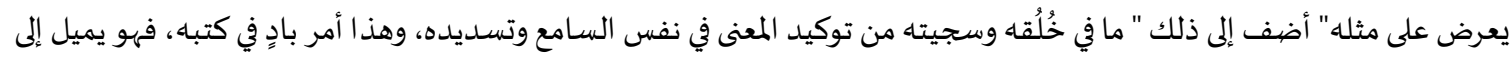
الإطناب والتكرار والتوسل إلى الإقناع بكل ما في وسعه " 98

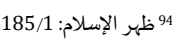
154/2، 95 الخصائص 96 97 98 الخصبائص،13/1، السابن، مقدمة المحقق 


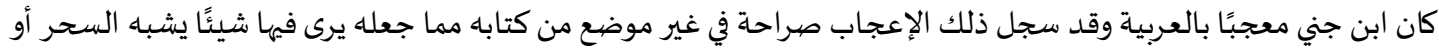

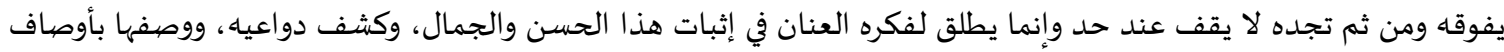

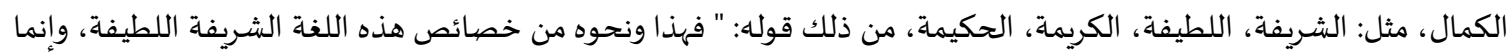

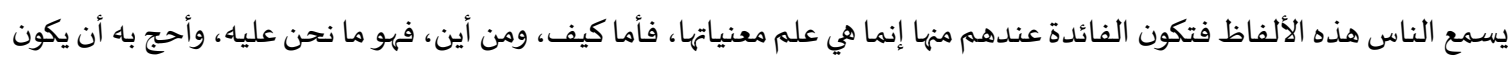

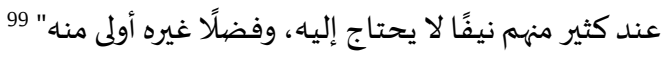

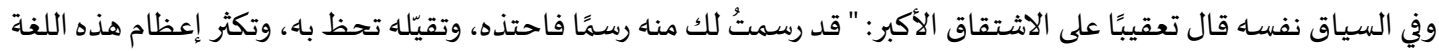

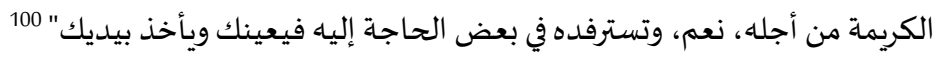

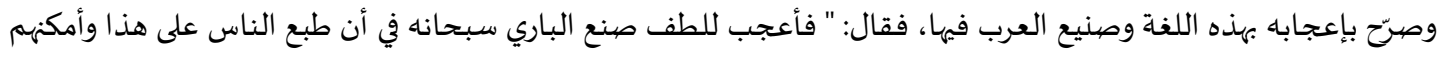

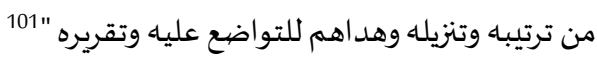

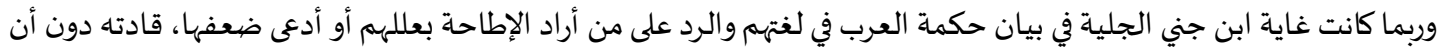

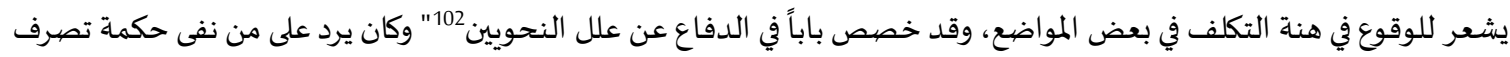

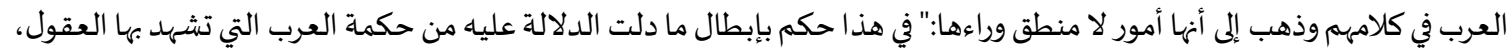

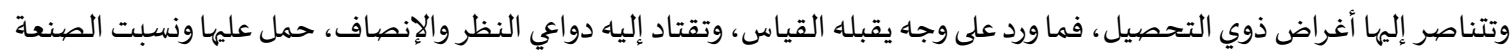

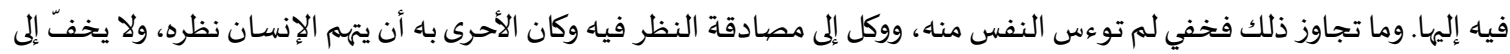

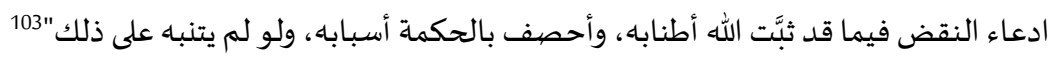

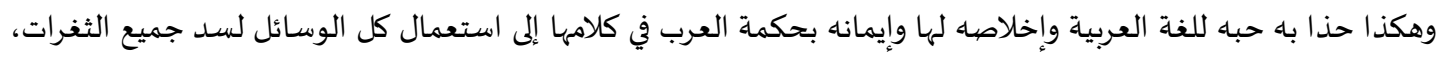

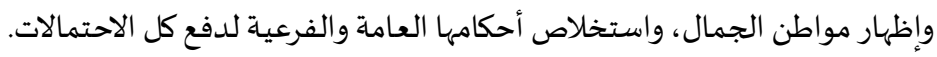

ثالثاً: طبيعة المرحلة العلمية والفترة الزمنية:

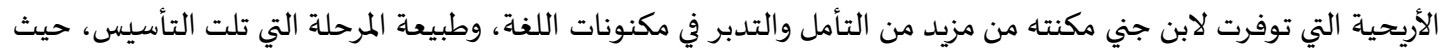

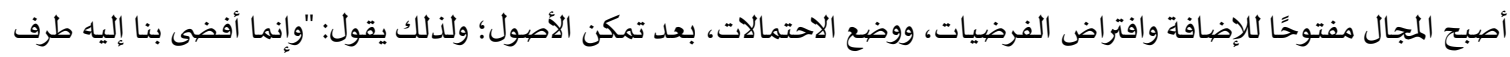

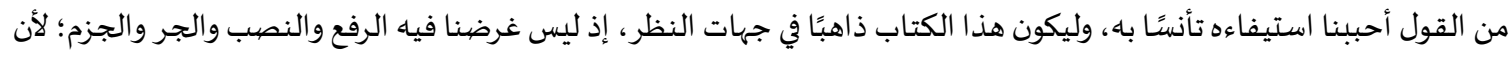

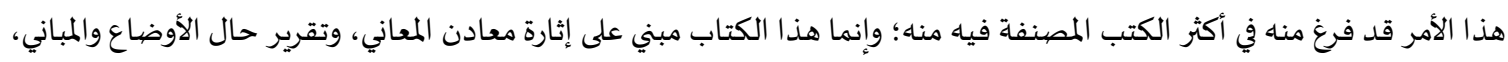

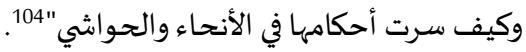

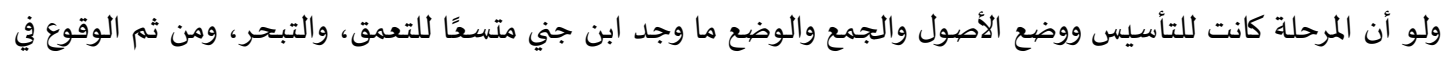

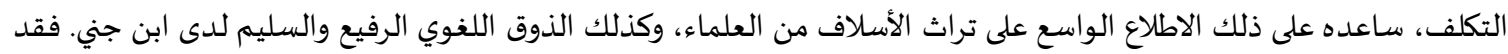

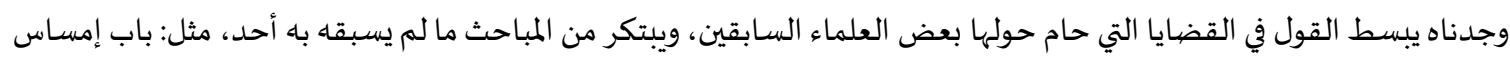

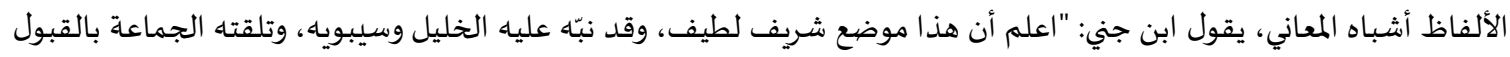

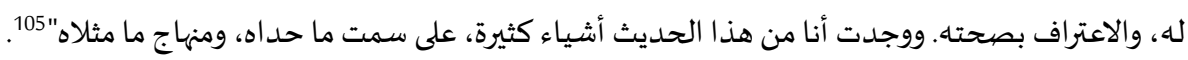

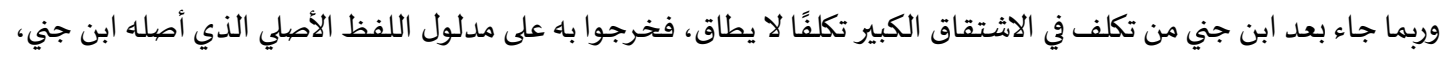

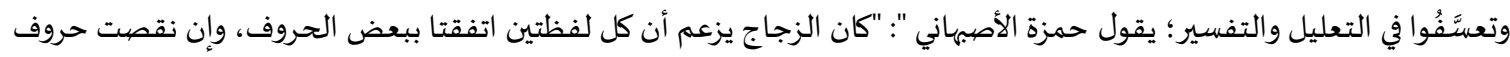

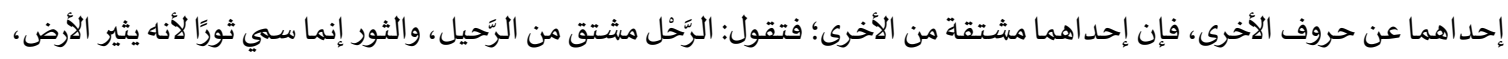

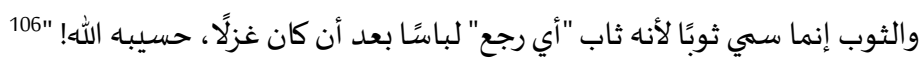

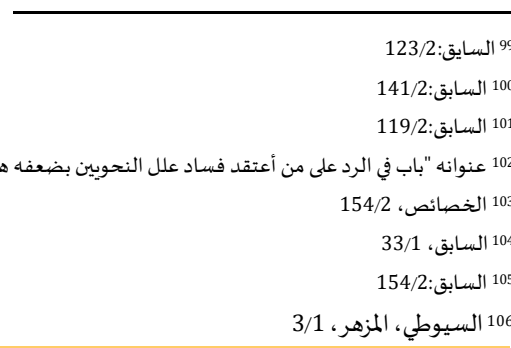


رغم براعة ابن جني في التعليل والتحليل ومقدرته اللغوية الفذة في معالجة القضايا اللغوية بصورة منطقية خاضعة للتصور العقلي إلا أنه لم يسلم من وصف بعض بعض اللغويين القدامى والمحدثين لله بالمبالغة في بعض القضيايا، ولعل أكثر كلمة كانت تستعمل

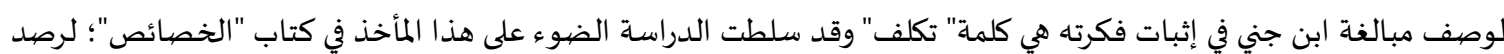
مظاهره، والكشف عن أسباباه، ويمكن القول إنها أسفرت عن نتائج، من أهمها الآتي: أبرزت الدراسة التكلف الاشتقاقي بوصفه مظهرًا من أكثر مظاهر التكلف حضورًا؛ وقد كان ولوع ابن جني بالاشتقاق سببًا في

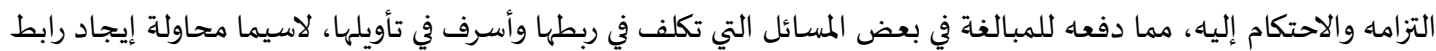
معنوي مشترك لجميع الجذور الناتجة عن تقليب المادة الواحدة، فيما سماه "الاشتقاق الأكبر". مما تعزى له أكثر أسباب التكلف وترد إليه أن ابن جني كان يحاول أن يقلل دائما من مساحة التباين في اللغة، وكأن التباين بين

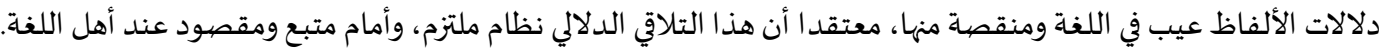
أظهرت الدراسة أن تبني ابن جني لمبدأ ارتباط أصهوات الألفاظ بمعانيها كان مسؤولا عن أهم آراء ابن جني، ورافدًا رئيسًا للتكلف

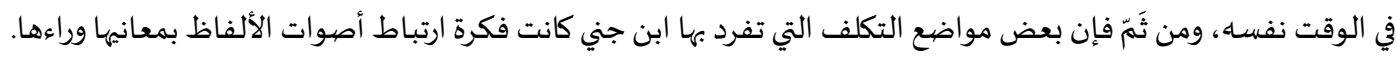
من مظاهر التكلف التي رصدتها الدراسـة محاولة ربط ترتيب حروف اللفظ بمعناهوبالحدث المعبَّر عند، استنادًا على مبدأ القيمة التعبيرية للحرف، وهو مظهر يقود التسليم بمبادئه إلى التناقض مع نظرية الاشتقاق الكبير التي نادى بها ابن جني، وأقامها على ملى مئل

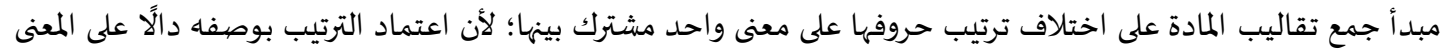
ومؤشر عليه يبنى عليه أن اختلاف الترتيب يؤدي إلى اختلاف المعنى وتغيير مساره، وبذا قاد تكلف ابن جني إلى تناقضيه من طرف أسهمت عقلية ابن جني التحليلية التعليلية من ناحية وشخصيته الفذة المبدعة من ناحية أخرى في إيجاد قدر من التكلف، فهو

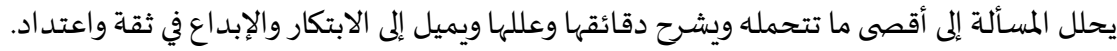
كان إعجاب ابن جني باللغة وصنيع العرب، وسعيه الحثيث إلى بيان حكمة العرب في لفتهم والرد على من أراد الإطاحة بعللهم أو أدعى ضعفها من أسباب الوقوع في مضيق التكلف بابه

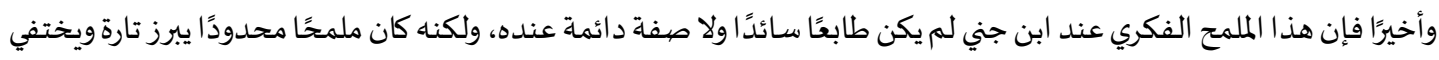

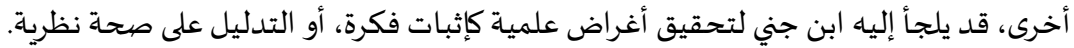

1. الأصفهاني، أبو القاسم الحسين بن محمد المعروف بالراغب الأصفهاني (1412ه). تح: صفوان الداودي، دار القلم، الدار الشامية - دمشق بيروت. 2. أمين، احمد (2013). ظهر الإسلام. مؤسسة هنداوي للتعليم والثقافة، مصر.

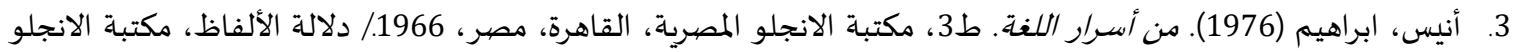
المصرية، طط3، القاهرة. 4. البستاني، بطرس (1883). دائرة المعارف. طبعة بيروت.

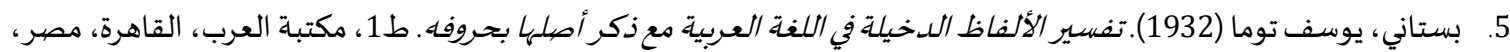

6. بلعرج، بلقاسم بن أحمد (2002). ظاهرة تعليل الألفاظ. مجلة الدراسات اللغوية: مركز الملك فيصل للبحوث والدراسات الاسلامية،

7. الثعالبي، عبد الملك (1403هـ). يتيمة الدهرفي محاسن أهل العصر. ت: مفيد محمد قميحة، ط1، دار الكتب العلمية. 8. ابن جني، أبو الفتح عثمان (1421هـ). سر صناعة الإعراب. ت: حسن هنداوي، دار الكتب العلمية، بيروت، لبنان. 9. الخصائص، ط4، الهيئة المصبرية العامة للكتاب. 10. الجواليقي، أبي منصور موهوب بن أحمد (1410هـ). المعرب من الكالام الأعجمي. ط1، دار القلم، دمشق، سوريا. 
11. الجوهري، أبو نصر إسماعيل بن حماد (1407ه). الصحاح تاج اللغة وصحاح العببية. ت: احمد عبد الغفور عطار، ط4، دار العلم للملايين، بيروت، لبنان.

12. الزبيدي، محمّّد بن محمّد بن عبد الرزّاق الحسيني (1984). تاج العروس من جواهر القاموس. تح: مصطفى حجازي وآخرين، دار الهداية 13. الزجاجي، أبو القاسم (1406هـ). الإيضاح في علل النحو. ط5، دار النفائس، بيروت، لبنان.

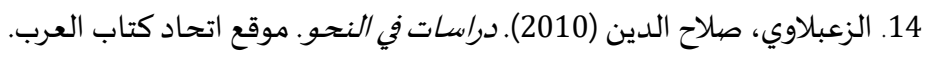

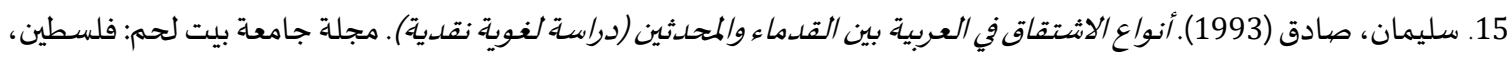

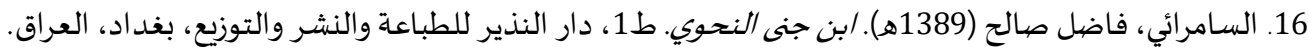

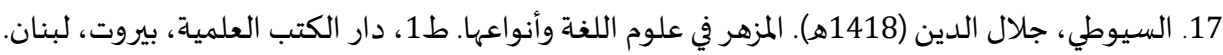

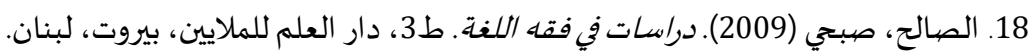

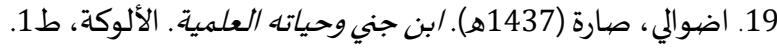
20. الطوسي، أبو حامد محمد بن محمد الغزالي (1390ه). شفاء الغليل في بيان الشبه والمخيل ومسالك التعليل. ط1، مطبعة الإرشاد، بغداد، العراق.

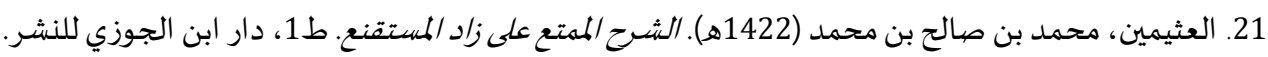

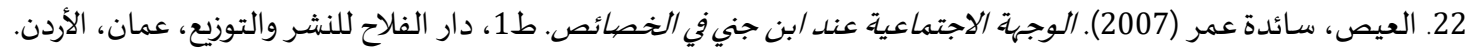

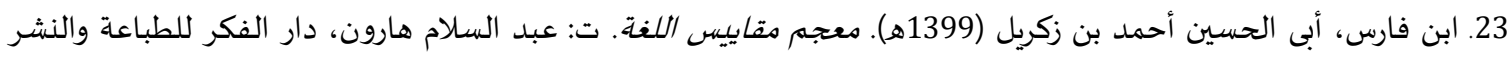
والتوزيع، بيروت، لبنان.

24. فندريس، جوزيف (1950). اللغة. تر: عبد الحميد الدواخلي، محمد القصاص الناشر: مكتبة الأنجلو المصرية.

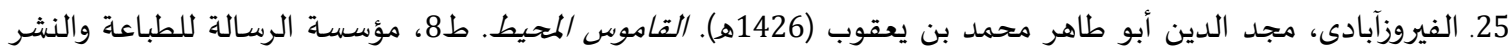
والتوزيع، بيروت، لبنان. 26. المبارك، محمد (1972). فقه اللغة وخصائص العببية. دار الفكر للنشر، بيروت، لبنان.

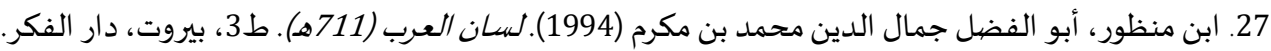

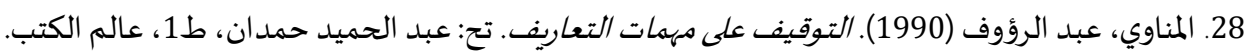

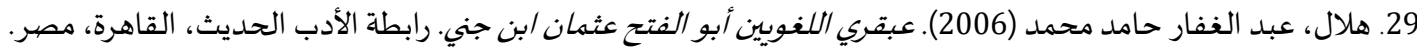

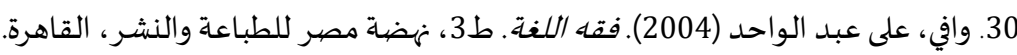

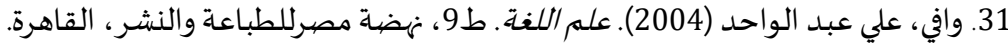

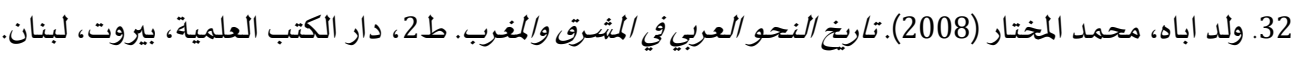


المجلة الدولية للدراسات اللغوية والأدبية العربية

International Journal for Arabic Linguistics and Literature Studies (JALLS)

www.refaad.com

Journal Homepage: https://www.refaad.com/views/JALS/home.aspx ISSN : 2663-5860(Online) 2663-5852(Print)

\title{
Ibn Jinni's linguistic Preciosity In "The book of Alkhasayis It's reasons \& demonstrations $(392 \mathrm{H})$
}

\author{
Amane Abdulaziz Aldawood \\ Associate Professor of Arabic Language, University of Jeddah, KSA \\ aaal-dawood@uj.edu.sa
}

Received: 7/7/2021 Revised: 21/7/2021 Accepted: 7/8/2021 DOI : https://doi.org/10.31559/JALLS2021.3.3.4

Abstract: Ibn Jinni's scientific status and linguistic preciosity were uttered by the testimonies of the earlier and later generations, and the investigators referred to it, his scientific status is unanimous, and there is no dispute or controversy over it, Hence, the nature of this study is different from other studies that dealt with Ibn Jinni aiming to shed light on one of the issues that were taken on him, and one aspect of the linguistic criticism that was directed at him is the slight preciosity with which he was marked by some scholars, ancient and modern.

The study tended to monitor that preciosity by examining its demonstrations as it emerged in Ibn Jinni, and trying to reveal the reasons that led Ibn Jinni to it, or led to his presence in his linguistic presentation and scientific thought, the reliance in determining these demonstrations and reasons were based on contemplation and explanation on the texts of Ibn Jinni and the approaches of his analysis examples, his presentation of theories, his judgment on them, and prolonged consideration of his thought approaches, and the foundations of his theorizing, in order to reach beyond that thought of the reason or justification, and It is being followed in which Ibn Jinni appeared affected or excessive in opinion, and studied it an objective study, which does not disregard his efforts and at the same time reveals an aspect of his personality that may be reflected in his linguistic presentation and justify a position taken towards him in some cases. The study highlighted derivational affectation as one of the most present aspects of affectation. Ibn Jinni's obsession with derivation was a reason for his commitment and appeal to it, and other aspects were observed, the most important of which are:

Attempting to link the order of the pronunciation letters with its meaning and expressed event, based on the principle of the expressive value of the letter, and the link between the meanings of the origins of synonyms, even if their meanings diverged, and rooting of some extraneous words. As for the most common reasons, it is attributed to the fact that Ibn Jinni was always trying to reduce the area of variation in the language, with what was distinguished by his analytical and explanatory mentality and his unique and creative personality.

He fully analyzes the issue that it can bear, and explains its subtleties and causes, and tends to innovate and create with confidence and pride, accompanied by strong admiration for the Arabic language, and a desire to express their wisdom.

Keywords: Ibn Jinni; Linguistic preciosity; Derivation; Matching words with meanings. 


\section{References:}

1. Al'thymyn, Mhmd Bn Salh Bn Mhmd (1422h). Alshrh Almmt' 'la Zad Almstqn'. T1, Dar Abn Aljwzy Llnshr.

2. Al'ys, Sa'dh 'Emr (2007). Alwjhh Alajtma'yh 'nd Abn Jny Fy Alkhsa's. T1, Dar Alflah Llnshr Waltwzy', 'man, Alardn.

3. Adwaly, Sarh (1437h). Abn Jny Whyath Al'lmyh. Alalwkh, T1.

4. Amyn, Ahmd (2013). Zhr Aleslam. M'sst Hndawy Llt'lym Walthqafh, Msr.

5. Anys, Abrahym (1976). Mn Asrar Allghh. T3, Mktbt Alanjlw Almsryh, Alqahrh, Msr, 1966/ Dlalt Alalfaz, Mktbh Alanjlw Almsryh, T3, Alqahrh.

6. Alasfhany, Abw Alqasm Alhsyn Bn Mhmd Alm'rwf Balraghb Alasfhany (1412h). Th: Sfwan Aldawdy, Dar Alqlm, Aldar Alshamyh - Dmshq Byrwt.

7. Bl'rj, Blqasm Bn Ahmd (2002). Zahrh T'lyl Alalfaz. Mjlt Aldrasat Allghwyh: Mrkz Almlk Fysl Llbhwth Waldrasat Alaslamyh, 4(2).

8. Albstany, Btrs (1883). Da'rt Alm'arf. Tb't Byrwt.

9. Bstany, Ywsf Twma (1932). Tfsyr Alalfaz Aldkhylh Fy Allghh Al'rbyh M' Dkr Aslha Bhrwfh. T1, Mktbt Al'rb, Alqahrh, Msr, 1932m.

10. Abn Fars, Aba Alhsyn Ahmd Bn Zkryl (1399h). M'jm Mqayys Allghh. T: 'Ebd Alslam Harwn, Dar Alfkr Lltba'h Walnshr Waltwzy', Byrwt, Lbnan.

11. Fndrys, Jwzyf (1950). Allghh. Tr: 'bd Alhmyd Aldwakhly, Mhmd Alqsas Alnashr: Mktbh Alanjlw Almsryh.

12. Alfyrwzabada, Mjd Aldyn Abw Tahr Mhmd Bn Y'qwb (1426h). Alqamws Almhyt. T8, M'sst Alrsalh Lltba'eh Walnshr Waltwzy', Byrwt, Lbnan.

13. Hlal, 'bd Alghfar Hamd Mhmd (2006). 'bqry Allghwyyn Abw Alfth 'thman Abn Jny. Rabtt Aladb Alhdyth, Alqahrh, Msr.

14. Abn Jny, Abw Alfth 'thman (1421h). Sr Sna't Ale'rab. T: Hsn Hndawy, Dar Alktb Al'Imyh, Byrwt, Lbnan.

15. Aljwalyqy, Aby Mnswr Mwhwb Bn Ahmd (1410h). Alm'rb Mn Alklam Ala'jmy. T1, Dar Alqlm, Dmshq, Swrya.

16. Aljwhry, Abw Nsr Esma'yl Bn Hmad (1407h). Alshah Taj Allghh Wshah Al'rbyh. T: Ahmd 'bd Alghfwr 'tar, T4, Dar Al'Im Llmlayyn, Byrwt, Lbnan.

17. Alkhsa's, T4, Alhy'h Almsryh Al'amh Llktab.

18. Almbark, Mhmd (1972). Fqh Allghh Wkhsa's Al'rbyh. Dar Alfkr Llnshr, Byrwt, Lbnan.

19. Almnawy, 'bd Alr'wf (1990). Altwqyf 'la Mhmat Alt'aryf. Th: 'bd Alhmyd Hmdan, T1, 'alm Alktb.

20. Abn Mnzwr, Abw Alfdl Jmal Aldyn Mhmd Bn Mkrm (1994). Lsan Al'rb (711h). T3, Byrwt, Dar Alfkr.

21. Alsalh, Sbhy (2009). Drasat Fy Fqh Allghh. T3, Dar Al'elm Llmlayyn, Byrwt, Lbnan.

22. Alsamra'y, Fadl Salh (1389h). Abn Jna Alnhwy. T1, Dar Alndyr Lltba'h Walnshr Waltwzy', Bghdad, Al'raq.

23. Slyman, Sadq (1993). Anwa' Alashtqaq Fy Al'rbyh Byn Alqdma' Walmhdthyn (Drash Lghwyh Nqdyh). Mjlt Jam't Byt Lhm: Flstyn,

24. Alsywty, Jlal Aldyn (1418h). Almzhr Fy 'lwm Allghh Wanwa'ha. T1, Dar Alktb Al'lmyh, Byrwt, Lbnan.

25. Alth'alby, 'bd Almlk (1403h). Ytymh Aldhr Fy Mhasn Ahl Al'sr. T: Mfyd Mhmd Qmyhh, T1, Dar Alktb Al'lmyh.

26. Altwsy, Abw Hamd Mhmd Bn Mhmd Alghzaly (1390h). Shfa' Alghlyl Fy Byan Alshbh Walmkhyl Wmsalk Alt'lyl. T1, Mtb't Alershad, Bghdad, Al'raq.

27. Wafy, 'la 'bd Alwahd (2004). Fqh Allghh. T3, Nhdt Msr Lltba'h Walnshr, Alqahrh.

28. Wafy, 'ly 'bd Alwahd (2004). 'Im Allghh. T9, Nhdt Msrlltba'h Walnshr, Alqahrh.

29. Wld Abah, Mhmd Almkhtar (2008). Tarykh Alnhw Al'rby Fy Almshrq Walmghrb. T2, Dar Alktb Al'lmyh, Byrwt, Lbnan.

30. Alz'blawy, Slah Aldyn (2010). Drasat Fy Alnhw. Mwq' Athad Ktab Al'rb.

31. Alzbydy, Mhmd Bn Mhmd Bn 'bd Alrzaq Alhsyny (1984). Taj Al'rws Mn Jwahr Alqamws. Th: Mstfa Hjazy Wakhryn, Dar Alhdayh

32. Alzjajy, Abw Alqasm (1406h). Aleydah Fy 'll Alnhw. T5, Dar Alnfa's, Byrwt, Lbnan. 